\title{
EL INTERVENCIONISMO MILITAR DE FRANCIA EN ÁFRICA: UNA EUROPEIZACIÓN LIMITADA (1960-2019)
}

\author{
THE MILITARY INTERVENTIONISM OF FRANCE IN \\ AFRICA: A LIMITED EUROPEANIZATION (1960-2019)
}

\section{L'INTERVENTIONNISME DE LA FRANCE EN AFRIQUE: UNE EUROPÉISATION LIMITÉE (1960-2019)}

\author{
Aymeric Durez \\ Pontificia Universidad Javeriana \\ durezaymeric@gmail.com
}

Resumen: Tras la descolonización, Francia logró mantener relaciones estrechas con sus antiguas colonias del África subsahariana a través de acuerdos de cooperación económicos, culturales y militares. Gracias a éstos y a la permanencia de sus fuerzas militares en el continente, se impuso como el "protector" de los nuevos Estados, en el marco de la Guerra Fría, aun si para la ejecución de esta política no solía contar con el respaldo de sus socios europeos. Sin embargo, las críticas recibidas, en particular después del genocidio en Ruanda de 1994, incitaron a los dirigentes franceses a movilizar las herramientas nacientes de política exterior y de seguridad europea (PESC) para relegitimar su acción en África. Esta "europeización" de la política africana de Francia llevó al despliegue de misiones civiles y militares de la Unión Europea, si bien ello no bastó para restarle autonomía a los intereses franceses en África y borrar las divergencias con sus socios europeos.

Palabras clave: África, Francia, intervencionismo militar, Unión Europea, europeización.

ABSTRACT: Following decolonization, France sought to maintain close relations with its ancient African sub-Saharan colonies through economic, cultural and military cooperation agreements. Thanks to those agreements and to its military presence in Africa, France could impose itself as the "protector" of the new states in the frame of the Cold War. In order to implement this policy, France couldn't rely on the support of its European partners. However, the 
criticism of French African policy, especially after the Rwanda genocide in 1994, forced French leaders to mobilize the tools of the Common Foreign and Security Policy (CFSP) in order to legitimize French action in Africa. Although, this "Europeanization" of French African policy lead to the civil and military deployment of the European Union in the African continent, it was not enough to erase both French interests in Africa and its divergences with its European partners.

Keywords: Africa, France, military interventionism, European Union, Europeanization

\section{Traducción de Gonzalo Celorio Morayta}

RÉsumé : Après la décolonisation, la France a réussi à conserver des liens étroits avec ses anciennes colonies d'Afrique subsaharienne, moyennant des accords pour la coopération économique, culturelle et militaire. Grâce à ceuxci et à la permanence de ses forces armées sur le continent, elle s'est affirmée comme "protectrice" des nouveaux états dans le cadre de la guerre froide, même si pour déployer une telle politique elle ne comptait pas, la plupart du temps, sur l'appui de ses partenaires européens. Cependant, en réponse à des critiques provoquées surtout par le génocide au Rwanda en 1994, les hommes politiques français ont choisi d'utiliser les nouvelles ressources de la Politique étrangère et de sécurité commune (PESC) dans le but de légitimer à nouveau leur action en Afrique. Cette "européisation" de la politique française vis-à-vis de l'Afrique a impliqué le déploiement de missions civiles et militaires de l'Union Européenne, ce qui n'a pourtant pas suffi à limiter l'autonomie de la France dans la poursuite de ses intérêts, ni à effacer les désaccords avec ses partenaires européens.

Mots clefs: Afrique, France, intervention militaire, Union Européenne, européisation.

Traducción de Bernardo Mabire

Fecha de recepción: octubre de 2018

Fecha de aceptación: junio de 2019 
$\mathrm{E}$ 111 de enero de 2013, el presidente francés François Hollande decidió lanzar una intervención militar en Malí con el objetivo de poner fin a las conquistas territoriales de los grupos yihadistas Al Qaeda en el Magreb Islámico (AQMI), ${ }^{1}$ Ansar Dine ${ }^{2}$ y el Movimiento para la Unicidad y la Yihad en África Occidental (MUYAO). ${ }^{3} \mathrm{Al}$ igual que sus predecesores, aprovechó los poderes conferidos por la Constitución de la Quinta República y la puesta en práctica de las instituciones desde la presidencia del general De Gaulle, para tomar dicha decisión de manera solitaria, rodeado únicamente por algunos asesores diplomáticos y militares. ${ }^{4}$

Para su intervención en Malí, Francia pudo contar con una participación de tropas africanas, mediante el despliegue de la Misión Internacional de Apoyo a Malí (MISMA) y el envió de más de 2000 soldados de Chad. Por el contrario, la operación "Serval" estuvo caracterizada por la ausencia de participación europea, a excepción de ayudas materiales a nivel bilateral. En Francia, la oposición insistió sobre la ausencia de una respuesta común de la Unión Europea (UE) ${ }^{5}$ Esas críticas pusieron de relieve la importancia del tema de la europeización del intervencionismo militar de Francia y la deslegitimación del intervencionismo unilateral. ${ }^{6}$

Desde la primera operación de la UE en 2003, hasta 2013, se desplegaron en África trece operaciones de veintiséis. To-

${ }^{1}$ El 11 de septiembre de 2006, tres años después de haber jurado lealtad a Ben Laden, el Grupo Salafista para la Predicación y el Combate (GSPC), creado en 1998, tomó el nombre de AQMi. En 2007 hizo de Francia su principal blanco.

${ }^{2}$ Grupo islamista tuareg de orientación salafista que apareció en 2012.

${ }^{3}$ Grupo armado salafista que apareció al final de 2011, tras una escisión con AQMI.

${ }^{4}$ B. Irondelle, La réforme des armées en France, París, Les Presses de Sciences Po, 2011, pp. 209-215.

5 M. Gregor, Les guerres africaines de François Hollande, París, Éditions de l'Aube, coll. L'urgence de comprendre, 2014, pp.112-121.

${ }^{6}$ J. Howorth, "European Defence and the Changing Politics of the European Union: Hanging Together or Hanging Separately?", Journal of Common Market Studies, vol. 39, núm. 4 (2001), pp. 765-789. 
mando en cuenta únicamente las operaciones militares, fueron cinco de seis las que se desarrollaron en el mencionado continente. En los estudios sobre la política de Defensa de la UE, muchos autores han subrayado el liderazgo de Francia en la elaboración de la política de defensa europea en África subsahariana, en particular en los países francohablantes. ${ }^{7} \mathrm{Si}$ bien ciertos autores han demostrado la importancia de la dimensión normativa de las misiones desplegadas por la UE ${ }^{8}$ otros han mostrado que su decisión de intervenir dependía en gran medida de la voluntad de movilización de uno o varios Estados capaces de instrumentalizar el discurso normativo para obtener una acción de la UE. ${ }^{9}$ En el caso de la operación Serval, que movilizó hasta 4500 soldados franceses desplegados en una guerra ofensiva, el uso de un discurso ético de los gobernantes franceses -François Hollande, pretendiendo que Francia no tenía "ningún interés en Malí

${ }^{7}$ C. Gegout, "Causes and consequences of the EU's military intervention in the Democratic Republic of Congo: a realist explanation", European Foreign Affairs Review, 10, núm. 3 (2005), pp. 427-443. R. Marchal, An assessment of EUFOR Tchad/Car in Walter Feichtinger y Gerald Hainzl, Vienne: Institut fur Friedenssicherung und Konfliktmanagement, 2011, pp. 1933. A. Menon, "Empowering paradise? The ESDP at ten", International Affairs, 85, núm. 2 (2009), pp. 227-246.

${ }^{8}$ M.E. Smith, Europe's Foreign and Security Policy: The Institutionalisation of Cooperation, Cambridge, University Press, 2004. S. Lucarelli e I. Manners, I, Values and Principles in European Union Foreign Policy, Londres, Routledge, 2006. H. Sjursen, "Why Expand? The Question of Legitimacy and Justification in the EU's Enlargement Policy", JCMS: Journal of Common Market Studies, 40 (2002), pp. 491-513. M. Riddervold, "Finally, flexing its muscles? Atalanta - The European Union's naval military operation against piracy”, European Security, 20, núm. 3 (2014), pp. 385-404.

${ }_{9}^{9}$ R. H. Ginsberg, Foreign Policy Actions of the European Community The Politics of Scale, Boulder, Lynne Rienner Publishers, 1989. A. Mattelaer, The Strategic Planning of EU Military Operations - The Case of EUFOR TCHAD / RCA. IES, 5/ (Documento de trabajo), 2008. F. Schimmelfennig y D.C. Thomas, "Normative Institutionalism and EU Foreign Policy in Comparative Perspective", International Politics, 46, núm. 4 (2009), pp. 491-504. 
salvo el de la paz"10_ no bastó para lograr una movilización fuerte de los miembros de la UE. Por consiguiente, la operación francesa recordó las antiguas operaciones del tiempo de la Guerra Fría, cuando Francia actuaba de manera unilateral como gendarme de África, en nombre de la lucha contra el comunismo.

Este papel tradicional de Francia, desde la época de las independencias, puede comprenderse con el concepto de "rol", introducido en el análisis de la política exterior por Kalevi J. Holsti en 1970. El rol corresponde a la idea que se hacen los dirigentes de los Estados sobre un conjunto de decisiones, compromisos y reglas de comportamiento que corresponden a su Estado, así como de la función que éste debe cumplir a largo plazo en el sistema internacional. ${ }^{11} \mathrm{El}$ rol no es un dato objetivo, pero su característica es que a la vez es el producto del estatuto real del Estado y de factores ideacionales. ${ }^{12}$ En su estudio efectuado entre los años de 1965 y 1967, K. Holsti identificó una decena de roles posibles para un Estado en materia de política exterior: bastión de la revolución; líder regional; protector regional; independiente activo; abogado de los movimientos de liberación; agente antiimperial; defensor de un sistema de valores; mediador-integrador; colaborador del sistema subregional; puente entre varios Estados y culturas; fiel aliado; independiente; ejemplo; desarrollado en el ámbito interno; protegido. ${ }^{13}$

En 1960, al reconocer la soberanía de sus antiguas colonias en África occidental y central, tras no haber podido conven-

${ }^{10}$ Vœux à la presse de F. Hollande, 16 de enero de 2013. Déclaration de F. Hollande, sur l'intervention militaire française au Mali, París, 12 de enero de 2013 ; Vœux du Président de la République, Tulle, 19 de enero de 2013.

${ }^{11}$ K. J. Holsti, "National Role Conception in the Study of Foreign Policy”, International Studies Quarterly, 14, núm. 3 (1970), pp. 233-309.

12 Paul V. Larson, W. Wohlforth, Status in World Politics, Cambridge, University Press, 2014, p. 7-13. N. del E. El término ideacionales corresponde a la teoría constructivista de las relaciones internacionales y se refiere al papel de las ideas como modeladoras del sistema internacional.

${ }^{13}$ Holsti, art. cit. 
cerlas de mantenerse en la comunidad francesa establecida en $1958,{ }^{14}$ Francia se vio obligada abandonar el rol de potencia imperial. Sin embargo, al firmar acuerdos de cooperación con estos nuevos Estados soberanos, que incluían un componente militar, logró hacerse de un nuevo rol de protector regional. Entre Francia y sus socios de África subsahariana se instauró una relación clientelista. A cambio de su ayuda y de la protección de los regímenes vigentes, Francia esperaba mantener una relación económica y política privilegiada. ${ }^{15} \mathrm{La}$ noción de "pré carré" (coto privado) permitió formalizar el lazo entre el rol de protector que respaldaba Francia y el espacio constituido por los países de la antigua comunidad francesa. ${ }^{16}$ Según la definición aprobada por Jacques Foccart, secretario general para los asuntos africanos y malgaches durante las presidencias del general De Gaulle y de Georges Pompidou, la política del pré carré consistía en "consolidar el poder de los dirigentes jugando de manera leal el juego de la amistad franco-africana [...]; hacer sentir la mordaza a los que miran demasiado en otras direcciones; contrarrestar al mismo tiempo los designios de las potencias rivales cuando se les juzga como amenazas". ${ }^{17}$

Esta definición subraya la importancia de la dimensión militar como garantía suprema de la protección de los regímenes africanos. Partiendo de la presencia continua de ope-

${ }^{14}$ La comunidad francesa se componía por siete Estados de la antigua África occidental francesa (Senegal, Sudán, Costa de Marfil, Dahomey, Níger, Alto Volta, Mauritania), cuatro Estados de la antigua África ecuatorial francesa (Congo, Ubangui-Chari, Chad, Gabón) y la isla de Madagascar.

15 J. F. Médard, "Le rapport de clientèle du phénomène social à l'analyse politique”, Revue française de science politique, año 26, núm. 1 (1976), p. 108. W. P. Veenendaal, "Analyzing the foreign policy of microstates: the relevance of the international Patron-Client model”, Foreign Policy Analysis, 13 (2017), pp. 561-577.

16 J. P. Bat, Le Syndrome Foccart: la politique française en Afrique, de 1959 à nos jours, París, Gallimard, 2012, p. 81.

${ }^{17}$ P. Biarnés, Les Français en Afrique noire: de Richelieu à Mitterrand: 350 ans de présence française au sud du Sahara, París, Armand Colin, 1987. J. Foccart, Foccart parle, entretiens avec Philippe Gaillard, t. I, París, Fayard, Jeune Afrique, 1995, p.218. 
raciones militares francesas en África, este artículo intentará medir la importancia del surgimiento de una dimensión europea. Mediante el cruce de numerosas fuentes sobre la política africana y europea de Francia y también de investigaciones en los archivos presidenciales para el periodo anterior a la década de 1990, este trabajo plantea que la europeización del intervencionismo militar en África francófona no ha generado una transferencia del rol de protector de Francia hacia Europa. Por el contrario, la europeización se caracteriza por ser de baja intensidad y tener un alcance limitado dentro de una división del trabajo con la política unilateral de Francia.

En este trabajo no se analizarán los mecanismos de decisión y de acción de las instituciones europeas ni los resultados de sus intervenciones, sino que se tratará de ver cuándo y por qué razones Francia procedió a una europeización de su intervencionismo militar en su pré carré. Por consiguiente, la "europeización" se entenderá no como la transferencia del modelo político y de las ideas europeas al ámbito nacional en los distintos países miembros (europeización top down), sino más bien como la transferencia de las preferencias nacionales en el ámbito europeo (europeización bottom $u p) .{ }^{18}$ Del debate sobre la regionalización de la política exterior, lo que nos interesa es observar cómo y cuándo Francia buscó tener una legitimación/normalización de su rol de protector regional en su pré carré, gracias a una acción en el marco de la uE. ${ }^{19}$ Este enfoque puede justificarse por tres razones principales:

1. El intervencionismo de Francia en su pré carré, y el endoso del rol de protector precedió las intervenciones europeas en África.

2. Las operaciones civiles y militares de la UE desplegadas desde 2003 todavía dependen del poder de decisión e inter-

${ }^{18}$ K. Featherstone y C. Radaelli, The Politics of Europeanization, Oxford, University Press, 2003.

${ }^{19}$ F. Charillon, "Vers la régionalisation de la politique étrangere", en F.Charillon, F. (dir), Politique étrangère: nouveaux regards, París, Presses de Sciences Po, 2002, p. 403. 
vencionista de los principales Estados. El nivel de integración y el papel de las instituciones comunitarias en materia de política de defensa está muy por debajo de otras dimensiones de la política africana de la UE, como por ejemplo lo que concierne a la ayuda oficial para el desarrollo. ${ }^{20}$

3. En cada intervención civil o militar de la uE en el pré carré de Francia, pudo demostrarse el papel clave de los dirigentes franceses para obtener la participación europea y definir los objetivos de su misión. ${ }^{21}$

Para estudiar la evolución en el desempeño del rol de protector regional y ver en qué momentos los dirigentes franceses han podido hacer uso de la palanca europea, se prestará atención tanto a los efectos de los cambios del entorno internacional, en particular el fin de la Guerra Fría, como a la evolución de la relación entre Francia y su pré carré. En la medida en que la Quinta República se presenta como un modelo de "Estado fuerte", donde el ejecutivo dispone de un margen de maniobra particularmente grande en materia de política exterior y de defensa, el trabajo se centrará sobre las decisiones tomadas por los cinco presidentes y por sus asesores más importantes dentro del Secretariado General para los Asuntos Africanos y Malgaches (SGAM) entre 1962 y 1974, y luego dentro de la célula africana del Elíseo. ${ }^{22}$

${ }^{20}$ C. Bué, "La politique de développement de l'Union européenne: réformes et européanisation”, Critique internationale, núm. 53 (2011), pp. 83-99.

${ }^{21}$ A. Mattelaer, op.cit.; B. Charbonneau, "Dreams of Empire: France, Europe, and the New Interventionism", Africa, Modern E Contemporary France, 16, núm. 3 (2008), pp. 279-295. T. Chafer y G. Cumming, "Beyond Fashoda: Anglo-French security cooperation in Africa since Saint-Malo”, International Affairs, 86, núm. 5 (2010), pp. 1129-1147. H. Dijkstra, "The military operation of the EU in Chad and the Central African Republic: good policy, bad politics”, International peacekeeping, 17, núm. 3 (2010), pp. 395-407. T. Koepf, "Interventions françaises en Afrique: la fin de l'européanisation?”, Politique étrangère, núm. 2 (2012), pp. 415-426.

${ }^{22}$ Dentro de los numerosos estudios que subrayan el alto margen de maniobra del ejecutivo francés, en particular si se le compara con el ejecutivo estadounidense, véase: S. Krasner, Defending the National Inter- 
En la primera parte se presentará cómo, tras el fracaso de la Comunidad Europea de Defensa (CED), el rol de protector de Francia en sus antiguas colonias se consolidó sin tener en cuenta la dimensión europea. La segunda parte mostrará cómo la nueva Guerra Fría que surgió al fin de los años setenta reforzó ese papel de protector, mientras que el fin de la Guerra Fría lo hizo más frágil, abriendo la puerta a la europeización de la política africana de Francia. ${ }^{23}$ En la tercera parte se presentará de qué manera esta europeización sirvió como un remedio a la crisis del papel de protector de Francia, tras el genocidio ruandés, mientras que la operación Serval puso de manifiesto una relegitimación del rol de protector regional de Francia y el papel segundario de la UE. Para lograr una mejor comprensión de la evolución del rol de protector regional de Francia en su pré carré, las principales operaciones militares desde 1960 hasta la actualidad se presentarán en cuadros donde aparecerá una descripción de cada intervención, precisando cuándo hubo una participación europea y de otros actores.

El intervencionismo Militar de Francia EN África: EL PRÉ CARRÉ SIN EUROPA

En el verano de 1950, para responder al deseo de Estados Unidos de obtener una mayor participación de los europeos en

est: Raw materials investments and US foreign policy, Princeton, University Press, 1978. T. Risse, "Public opinion, domestic structure and foreign policy in liberal democracies", World politics (1991), vol. 43, núm. 4, pp. 479-512. P. Katzenstein, International relations and domestic structures. International Organization, vol. 31, 4, (2009), pp. 1-45. Y. Mény y Y. Surel, Politique comparée les démocraties: Allemagne, États-Unis, France, Grande-Bretagne, Italie, París, Montchrestien, 2009.

23 Por "nueva Guerra Fría" se entiende el crecimiento de las tensiones entre los dos bloques a partir del fin de los años setenta, como consecuencia principalmente de la crisis de los euromisiles en Europa y de la invasión de Afganistán por los soviéticos. 
favor de la defensa de Europa occidental, el gobierno francés propuso crear una Comunidad Europea de Defensa (CED) con un ejército integrado, bajo un mando común y con garantía mutua en caso de agresión. Sin embargo, el 30 de agosto de 1954, la Asamblea Nacional francesa rechazó el proyecto.

Si bien es cierto que la disminución de la amenaza soviética, con el fin de la guerra de Corea y la muerte de Stalin, tuvo un papel determinante en la toma de la decisión mencionada, las causas esenciales de ésta provenían de la voluntad francesa de conservar una política de defensa independiente. En el combate contra la adopción de la CED, liderado por los comunistas y los gaullistas, se rechazó a la vez que el lugar de Francia quedara relegado en comparación con los anglosajones; la perspectiva del rearme alemán y la exigencia de acordar prioridad a las fuerzas integradas en la CED sobre las fuerzas desplegadas fuera del espacio europeo. ${ }^{24}$ Así, el proyecto se percibió en forma negativa para los tres círculos de la política exterior francesa: el círculo transatlántico, el europeo y el del "grand large".

\section{Una Europa política como alternativa efimera durante el proceso de descolonización}

Tras el voto de la Asamblea Nacional francesa, el "no" fue superado con la firma de los acuerdos de París el 23 de octubre de 1954, que provocó la entrada de la República Federal Alemana (RFA) en la Organización del Tratado del Atlántico del Norte (OTAN) y la mutación de la Unión Occidental, constituida el 17 de marzo de 1948 por Francia, el Reino Uni-

${ }^{24}$ C. Cogan, "Puissance virtuelle: la France de la victoire à l'OTAN", en M. Vaïsse, P. Mélandri, F. Bozo, La France et l'OTAN (1949-1966), Éditions Complexe, Bruselas, 1996, p. 73. J.M. Palayret, "Les mouvements proeuropéens et la question de l'Eurafrique, du Congrès de la Haye à la Convention de Yaoundé (1948-1963)", en M.T. Bitsch, G. Bossuat (dir.), L'Europe unie et l'Afrique: de l'idée d'Eurafrique à la convention de Lomé I, Bruselas, Bruylant, 2005, p. 203. 
do y los países del Benelux a la Unión de Europa Occidental (UEO) para integrar la RFA e Italia. Con respecto a la construcción europea, los desafíos económicos acabaron por sacar ventaja sobre los asuntos político-militares con la firma de los tratados de Roma el 25 de marzo de 1957. A costa de negociaciones tensas con sus socios, Francia logró obtener la inclusión de sus colonias en los mecanismos de los Tratados de Roma. ${ }^{25}$ Sin embargo, durante un encuentro con Adenauer el 14 de septiembre de 1958, De Gaulle admitió la existencia de "fuerzas centrífugas" que empujaban a Alemania "hacia Prusia" y a Francia "hacia África". ${ }^{26}$ Focalizada en su guerra en Argelia, Francia se contentó con presionar a sus socios europeos para que actuaran de manera solidaria, ayudándola en su lucha contra la política de internacionalización del conflicto. A pesar de tales esfuerzos, los europeos entendían con dificultad la permanencia de la presencia francesa en Argelia ${ }^{27}$.

Enfrentado la determinación de los revolucionarios argelinos y una presión diplomática creciente, De Gaulle se vio obligado a proclamar el derecho a la autodeterminación para Argelia el 16 de septiembre de $1959^{28} \mathrm{y}$, a partir de este momento, el proyecto europeo volvió al primer plano de la

25 D. Dimier, "Construire l'association de la communauté européenne et de l'Afrique indépendante", Matériaux pour l'histoire de notre temps, núm. 77 (2005).

${ }^{26}$ Procès-verbal de l'entretien entre de Gaulle et Adenauer, 14 septembre 1958, DDF, 1958, t. II, núm. 155.

27 M. Vaïsse, La Grandeur: politique étrangère du général de Gaulle, París, CNRS Éditions, 2013, [1998], pp. 63-65. R. Raimero, "L'Italie entre amitié française et solidarité algérienne”, en J.P. Rioux (dir), La guerre d'Algérie et les français, colloque de l'Institut d'histoire du temps présent (Paris, 15-17 décembre 1988), París, Fayard, 1990, pp. 389-396. D. Masset, Une affaire internationale?, la Belgique et la guerre d'Algérie, 1954-1956, Louvain-laNeuve, Ciaco, 1988.

${ }^{28}$ M. Harbi, Les archives de la révolution algérienne, París, Jeune Afrique, 1981. B. Stora, Le mystère de Gaulle: son choix pour l'Algérie, París, Robert Laffont, 2009. M. Connelly, L'arme secrète du FLN, París, Payot et Rivages, 2014. 
política exterior francesa. A medida que la situación en Argelia se encaminaba hacia la independencia, parecía más importante para el general De Gaulle basar la potencia francesa sobre un proyecto ambicioso a nivel europeo. Desde esta perspectiva, Francia lanzó la idea de reuniones periódicas de los ministros de Asuntos Exteriores de los seis países. ${ }^{29}$ Así, durante un encuentro en Rambouillet, el 29 y 30 de julio de 1960, De Gaulle y Adenauer acordaron establecer un mecanismo de coordinación entre Estados miembros y, en febrero de 1961, los trámites de Francia llevaron a la puesta en marcha de una comisión de estudio dirigida por Christian Fouchet.

La reorientación de la política exterior francesa hacia Europa tenía también como objetivo suscitar una nueva atracción de los países del Sur. ${ }^{30}$ En este sentido, De Gaulle propuso organizar debates europeos sobre África y América del Sur. Para el mandatario francés, Europa tenía vocación de servir como palanca para un acercamiento con el "tercer mundo" y para tener mayor independencia frente a EE.uU. Sin embargo, Francia no pudo convencer a sus socios y, el 17 de abril de 1962, los ministros de los Asuntos Exteriores tomaron nota de sus desacuerdos sobre el proyecto de una Europa política. Durante los años siguientes, no existió voluntad de lanzar nuevos proyectos en materia de política exterior y defensa europea. ${ }^{31}$

El intervencionismo francés en África en el centro de una politica de "manos libres"

En la medida en que su visión de Europa como concierto de los Estados y como entidad independiente de EE.UU. no era

29 Télégr de Couve de Murville aux représentations diplomatiques de France à Bruxelles, La Haye, Luxembourg et Bonn, DDF, 1959, t. II, núm. 112.

${ }^{30}$ C. de Gaulle, Discours et messages. I, Pendant la guerre : junio de 1940-enero de 1946, París, Plon, 1993, pp. 285-304.

${ }^{31} \mathrm{~S}$. Keukeleire y J. MacNaughtan, The Foreign policy of the European Union, Palgrave Macmillan, 2008, pp. 35-65. 
compartida por los otros países de la Comunidad Europea, De Gaulle no buscó un acuerdo a cualquier costo. ${ }^{32}$ Fuerte económicamente y poseedora del arma nuclear, Francia ocupaba de facto, un lugar privilegiado en Europa. Además, a nivel de la política del "grand large", en razón de la firma de acuerdos bilaterales con sus socios de África subsahariana y del avance de las negociaciones con el Frente de Liberación Nacional (FLN) en Argelia, Francia ya no necesitaba una alternativa europea.

Así, tras el fracaso del plan Fouchet, De Gaulle se contentó con preservar la dinámica de acercamiento con Alemania, firmando un tratado de amistad el 22 de enero de $1963 .{ }^{33}$ Sin embargo, el 15 de junio, el Bundestag añadió un preámbulo al tratado para precisar que éste no debía poner en peligro la defensa común en la Alianza Atlántica y tampoco una futura participación de Gran Bretaña en la Comunidad Económica Europea, cEE.

Posteriormente, Francia privilegió una política de "manos libres" encaminada a rechazar su participación en sistemas integrados, bien fuera a nivel de la oTAN o de las comunidades europeas. En este contexto, la política de cooperación de Francia con sus antiguas colonias fue elevada al rango de "gran ambición francesa" por el general De Gaulle. En el marco de esta política, la utilidad de la construcción europea quedó limitada a una dimensión comercial, debido a los acuerdos de Yaundé, firmados en 1963. Por el contrario, a nivel de los asuntos políticos y de defensa, Francia se apoyaba sobre sus acuerdos bilaterales de defensa y no esperaba nada de Europa. ${ }^{34}$

Desde las independencias, el sistema de defensa francés se organizó con fuerzas estacionadas en bases ubicadas en

32 M. Vaïsse, op.cit., 2013, p. 190. E. Jouve, Le général de Gaulle et la construction de l'Europe (1940-1966), París, LGDJ, 1967, p. 339.

33 C. Defrance y U. Pfeil, Le traité de l'Élysée et les relations franco-allemandes, 1945-1963-2003, París, CNRS éditions, 2005, pp. 73-87.

${ }^{34}$ F. Turpin, De Gaulle Pompidou et l'Afrique, 1958-1974, Décoloniser et coopérer, París, les Indes savantes, 2010, p. 186. 
zonas estratégicas (en los alrededores de los puertos y los aeródromos) y de fuerzas de intervención inmediata basadas en Francia. ${ }^{35}$ El control en materia de seguridad estaba garantizado también de manera cotidiana, gracias a los servicios de inteligencia con base en las capitales africanas. ${ }^{36}$ Estos dispositivos buscaban permitir prever las crisis y disuadir las operaciones de desestabilización de los poderes establecidos. ${ }^{37}$ Sin embargo, a pesar de preferir una acción discreta, Francia intervino varias veces a través de la inteligencia y la formación de las fuerzas africanas.

\section{CUAdro 1}

Las intervenciones militares francesas en África bajo las presidencias del general De Gaulle (1958-1969) y de Georges Pompidou (1969-1974)

\begin{tabular}{|c|c|c|c|c|}
\hline País & Periodo & Objetivos & $\begin{array}{l}\text { Participación } \\
\text { europea }\end{array}$ & $\begin{array}{l}\text { Otros aliados; } \\
\text { resolución del } \\
\text { CSNU; Operación de } \\
\text { la ONU }\end{array}$ \\
\hline $\begin{array}{l}\text { Guinea } \\
\text { Operación } \\
\text { Persil }\end{array}$ & 1958 & $\begin{array}{l}\text { Desestabilizar el régimen de } \\
\text { Sékou Touré que se negó a } \\
\text { formar parte de la comunidad } \\
\text { francesa en } 1958 \text {. }\end{array}$ & $\mathrm{X}$ & \\
\hline Camerún & 1960 & $\begin{array}{l}\text { Apoyar al presidente Ahidjo en } \\
\text { su lucha en contra de la Unión } \\
\text { de las Poblaciones del Camerún } \\
\text { (UPC). }\end{array}$ & $\mathrm{X}$ & \\
\hline $\begin{array}{l}\text { Congo } \\
\text { Kinshasa }\end{array}$ & 1960-1964 & $\begin{array}{l}\text { Apoyar de forma clandestina la } \\
\text { secesión del Katanga. }\end{array}$ & $\mathrm{X}$ & \\
\hline
\end{tabular}

35 P. Chaigneau, La politique militaire de la France en Afrique, París, CHEAM, 1984, p. 51.

36 P. Bat, op.cit., p. 184.

37 Turpin, op.cit., p. 204. Bat, op.cit., p. 249. 


\begin{tabular}{|l|l|l|l|l|}
\hline Gabón & $\begin{array}{l}19 \text { de } \\
\text { febrero de } \\
1964\end{array}$ & $\begin{array}{l}\text { Restablecer al presidente Léon } \\
\text { Mba, víctima de un golpe de Es- } \\
\text { tado militar. }\end{array}$ & X & \\
\hline Nigeria & $\begin{array}{l}\text { Enero de } \\
1968 \text {-abril } \\
\text { de } 1969 .\end{array}$ & $\begin{array}{l}\text { Apoyar el movimiento secesionis- } \\
\text { ta en Biafra, tras la proclamación } \\
\text { de su independencia el 30 de } \\
\text { mayo de 1967. }\end{array}$ & X \\
Gesta de Marfil,
\end{tabular}

Entre intervenciones limitadas a favor de las autoridades en el poder (Senegal), para restablecer el gobierno tras un golpe de Estado (Gabón), para apoyar un régimen frente a una rebelión armada (Chad) o para apoyar a un movimiento secesionista mediante una acción clandestina (Nigeria, Congo Kinshasa), las operaciones francesas se caracterizan por su "polimorfismo"y, por ello, resulta difícil establecer una “tipología". ${ }^{38}$ En varios casos, el general De Gaulle prefirió no intervenir en apoyo a un aliado, juzgando que tal interven-

38 Turpin, op.cit., p. 211. A. Dumoulin, La France militaire et l'Afrique, Bruselas, Complexe, 1997, p. 97. 
ción hubiese podido poner en tela de juicio la imagen de Francia tanto en África como a nivel internacional. Tal fue el caso, durante el derrocamiento del presidente Fulbert Youlou de la República del Congo, el 15 de agosto de 1963. En esta ocasión, De Gaulle aseguró que Francia no "podía tomar la responsabilidad" de intervenir militarmente en contra de la multitud cuando esta intervención causaría la muerte de "hasta mil o dos mil personas". ${ }^{39}$ Desde este punto de vista, la aplicación del rol de protector regional en el pré carré se vio matizado por los otros papeles que tenía Francia en el ámbito internacional, como el de "balancer" basado en la crítica del "imperialismo" de los dos grandes en el marco de la Guerra Fría y en la superación de la época del imperialismo europeo. ${ }^{40}$ Por el contrario, cuando el presidente francés consideró que la credibilidad del rol de protector del pré carré estaba en juego y que una intervención no pondría en gran peligro sus otros papeles a nivel internacional, las autoridades en París consideraban que tenían el poder y la responsabilidad de intervenir de forma unilateral. Tal fue el caso de la intervención en Gabón en 1964 y en Chad, en 1968-1969: "El Chad es una parte de la pared de nuestro edificio [...] es una parte carcomida, pero debe permanecer de pie". ${ }^{41}$

Adicionalmente a la voluntad de actuar como protector del pré carré, el punto común entre las intervenciones presentadas en el cuadro es que, en cada ocasión, Francia intervino de manera unilateral, sin buscar un mandato de la onU ni el apoyo activo de Estados Unidos y de sus socios europeos.

Durante esta época, en el plano militar, Francia no podía contar con el apoyo de la RFA, cuyo rearme dentro de la OTAN desde 1955 estaba enfocado en la defensa frente a la amenaza soviética. Entre los demás países, Bélgica es el úni-

${ }^{39}$ J.P. Bat, La fabrique des 'arbouzes', París, Nouveau monde éditions, 2015, pp. 342-346.

${ }^{40}$ Sobre este rol de "balancer" en la política exterior del general De Gaulle, véase K.J. Holsti, art. cit. p. 271.

${ }^{41}$ Citado por J. Foccart, op.cit., p. 306. 
co que tenía una política africana. Sin embargo, en el caso del Congo Kinshasa, los dos países se encontraban en una situación de competencia más que de cooperación. ${ }^{42}$ Desde inicios de 1960, frente a la perspectiva de la independencia del Congo Belga, De Gaulle habló de la necesidad de tomar posición en este país. ${ }^{43}$ En noviembre de 1964, el gobierno francés se negó a participar en la operación "dragon rouge", liderada por Estados Unidos y Bélgica para liberar la ciudad de Stanleyville. Para Francia, intervenir en África como ejecutante del bloque occidental, provocando a las potencias comunistas, era inconcebible. ${ }^{44}$

Dado lo anterior, la proximidad de EE.UU. con los socios europeos de Francia impedía iniciativas comunes. Así, Francia se negó a participar en un plan de reorganización del ejército congolés con Bélgica e Italia. ${ }^{45}$ En resumen, el aporte de Europa a la política francesa en África se limitó a los aspectos económicos y comerciales.

Un intervencionismo militar inmune a las dinámicas de la construcción europea

Al mismo tiempo que deseó mantener las grandes líneas de la política exterior del general De Gaulle, Georges Pompidou, electo presidente en 1969, quiso reorientar la diplomacia francesa hacia Europa. ${ }^{46}$ En este sentido, apoyó la adhesión

42 R. Yakemtchouk, La Belgique et la France, Amitiés et rivalités, París, L'Harmattan, 2010, pp. 171-175.

43 Note sur l'accord franco-belge de 1908 pour le Congo, 5 février 1960, Documents diplomatiques français, Tome II, 1er juillet -31 décembre, París, Impr. nationale, 1996, p. 216.

${ }^{44}$ Foccart, op.cit., p. 309. P.M. Durand, L'Afrique et les relations francoaméricaines des années soixante: aux origines de l'obsession américaine, París, L'Harmattan, 2017, p. 283.

45 Note de la sous-direction d'Afrique le 15 mars 1966, núm. 177, Documents diplomatiques français, Tome I, $1^{\circ}$ de enro-31 de mayo, PIE-Peter Lang, 2006.

${ }^{46}$ E. Roussel, Georges Pompidou, París, JC. Lattès, 1984. 
de Gran Bretaña en la cEe e impulsó el nacimiento de la Cooperación Política Europea (CPE) durante la cumbre europea de La Haya, en diciembre de 1969. Este proyecto permitió escuchar una voz independiente de Europa en el marco de la Conferencia para la Seguridad y la Cooperación en Europa (CSCE) y desarrollar una política autónoma en el mundo árabe, con el “dialogue euro-árabe, lanzado durante la Cumbre de Copenhague, en diciembre de $1973 .{ }^{47}$ Por el contrario, la creación de la CPE no condujo a una europeización de la política africana de Francia y mucho menos de su dimensión militar.

El interVENCIONISMO DESENFRENADO DE Francia EN EL MARCO DE LAS NUEVAS TENSIONES DE LA Guerra Fría Al FinAl de los años SETENTA

Si bien Francia apostó por Europa para defender su posición en el Medio Oriente, la política en África subsahariana dio continuidad a la época del general De Gaulle. ${ }^{48}$ A pesar de la salida de Mauritania y de Madagascar de la zona franco y de la apertura forzada de negociaciones para la revisión de acuerdos de cooperación, Francia no buscó europeizar su política africana. ${ }^{49}$ Por el contrario, en esa coyuntura en la cual "todo se estaba derrumbando", según las palabras de G. Pompidou, ${ }^{50}$ el gobierno francés escogió reunir una cumbre franco-africana con el objetivo de "reforzar la coherencia del conjunto franco-

${ }^{47}$ N. Badalassi, Adieu Yalta? La France, la détente et les origines de la Conférence sur la Sécurité et la Coopération en Europe, 1965-1975, (tesis doctoral inédita) Universidad París III, 2011.

48 J. Foccart, Journal de l'Elysée, Dans les bottes du général, t. III (19691971), París, Fayard, Jeune Afrique, 1999, p. 71.

49 J. Foccart, Foccart parle: entretiens avec Philippe Gaillard, t. II, París, Fayard, Jeune Afrique, 1997, pp. 79-80. Bat, op.cit., pp. 340-343.

${ }^{50} \mathrm{~J}$. Foccart, op.cit., 1999, p. 398. 
hablante". ${ }^{51}$ Durante esos años, la europeización quedó limitada al ámbito comercial, mientras que Francia siguió ejerciendo su papel de gendarme de África francófona, en particular en Chad (véase el cuadro 1).

Ahora bien, la continuidad global de la política africana de Francia no debe ocultar ciertas evoluciones durante la década de 1970, en especial frente a la caída del presupuesto de la política de cooperación y la adaptación a la creación de grupos regionales africanos, fundados sobre la cercanía geográfica, en vez de la unidad lingüística. ${ }^{52}$ Ciertas evoluciones del ámbito europeo alteraron la política africana de Francia. Desde esta perspectiva, tras la entrada del Reino Unido en la CEE en 1973, la firma de la convención de Lomé, el 28 de febrero de 1975, consagró la apertura de la cooperación europea hacia países fuera del pré carré francés. El 6 de junio de 1975, la designación de los Estados de África, Caribe, Pacifico (ACP) simbolizó la dinámica de mundialización de la ayuda. ${ }^{53}$

Sin embargo, esos cambios no pusieron en tela de juicio el rol de protector regional de Francia en su pré carré. Por el contrario, durante el mandato de Valéry Giscard d'Estaing (1974-1981), la ofensiva soviética en el contexto de la caída del imperio portugués en África y del régimen de Hailé Sélassié, en Etiopía, convirtieron a África en un foco de la confrontación Este-Oeste, provocando un mayor intervencionismo de Francia. 54

51 Télégramme n ${ }^{\circ}$ 596/600 de Jean Ribo le 30 août 1973, AN, 5AG(F) 3285. La primera cumbre tuvo lugar el 13 de noviembre de 1973.

${ }^{52} \mathrm{~J}$. Meimon, En quête de légitimité: Le ministère de la coopération (19591999) (tesis doctoral inédita), Universidad Lille II, 2005, p. 233.

53 A. S. Claeys, La France et la politique africaine de l'Europe (tesis doctoral inédita), Universidad Bordeaux IV, 2004, pp. 194-208.

${ }^{54}$ G.H. Soutou, La guerre froide, París, Fayard, 2013, pp. 820-827. M. Vaïsse, P. Melandri y F. Bozo, La France et l'OTAN (1949-1966), Bruselas, A. Versailles, 2012, pp. 587-589. 


\section{Cuadro 2}

\section{Las intervenciones militares francesas en África bajo el mandato de Valéry Giscard d'Estaing (1974-1981)}

\begin{tabular}{|c|c|c|c|c|}
\hline País & Periodo & Objetivo & $\begin{array}{c}\text { Participación } \\
\text { europea }\end{array}$ & $\begin{array}{l}\text { Otros aliados; } \\
\text { resolución del CSNU; } \\
\text { operación de la ONU }\end{array}$ \\
\hline $\begin{array}{l}\text { Benín } \\
\text { Operación } \\
\text { Crevette }\end{array}$ & $\begin{array}{l}16 \text { de enero } \\
\text { de } 1977\end{array}$ & $\begin{array}{l}\text { Provocar la caída del presidente } \\
\text { marxista Mathieu Kérékou con } \\
\text { una operación clandestina }\end{array}$ & $\mathrm{X}$ & $\begin{array}{l}\text { Marruecos, Togo, } \\
\text { Gabón }\end{array}$ \\
\hline $\begin{array}{l}\text { Zaire } \\
\text { Operación } \\
\text { Verveine }\end{array}$ & $\begin{array}{l}10 \text { de abril } \\
\text { de } 1977\end{array}$ & $\begin{array}{l}\text { Apoyar logísticamente una inter- } \\
\text { vención de boinas verdes marro- } \\
\text { quíes para poner fin a un movi- } \\
\text { miento secesionista en el Shaba }\end{array}$ & $\mathrm{X}$ & Marruecos \\
\hline $\begin{array}{l}\text { Mauritania } \\
\text { Operación } \\
\text { Lamentin }\end{array}$ & $\begin{array}{l}\text { Diciembre } \\
\text { de } 1977-\text { ju- } \\
\text { lio de } 1978\end{array}$ & $\begin{array}{l}\text { Defender el régimen mauritano } \\
\text { en guerra contra el frente Poli- } \\
\text { sario }\end{array}$ & $\mathrm{X}$ & \\
\hline $\begin{array}{l}\text { Chad } \\
\text { Operación } \\
\text { Tacaud }\end{array}$ & $\begin{array}{l}12 \text { de } \\
\text { marzo de } \\
1978-30 \text { de } \\
\text { mayo de } \\
1980\end{array}$ & $\begin{array}{l}\text { Tras haber desplegado una mi- } \\
\text { sión de asistencia técnica en } 1977 \\
\text { (operación "Camomille"), Fran- } \\
\text { cia lanza la operación "Tacaud", } \\
\text { con el objetivo de poner fin a la } \\
\text { ofensiva de las fuerzas de Oueddei } \\
\text { apoyadas por el coronel Gadafi }\end{array}$ & $\mathrm{X}$ & \\
\hline $\begin{array}{l}\text { Zaire } \\
\text { Operación } \\
\text { Bonite }\end{array}$ & $\begin{array}{l}17 \text { de mayo } \\
\text { de } 1978-21 \\
\text { de mayo de } \\
1978\end{array}$ & $\begin{array}{l}\text { Después de la toma del aero- } \\
\text { puerto de Kolwezi por el FNLC, } \\
\text { Francia lanza paracaidistas para } \\
\text { retomar la ciudad }\end{array}$ & Bélgica & $\begin{array}{l}\text { Después de la ope- } \\
\text { ración, despliegue } \\
\text { de una fuerza de } \\
\text { seguridad intera- } \\
\text { fricana }\end{array}$ \\
\hline $\begin{array}{l}\text { RCA } \\
\text { Operación } \\
\text { Barracuda }\end{array}$ & $\begin{array}{l}\text { Septiembre } \\
\text { de } 1979 \text {-ju- } \\
\text { nio de } 1981\end{array}$ & $\begin{array}{l}\text { En razón principalmente de su } \\
\text { acercamiento con el coronel } \\
\text { Gadafi, Francia interviene para } \\
\text { sacar el dictador Jean-Bedel } \\
\text { Bokassa del poder }\end{array}$ & $\mathrm{X}$ & \\
\hline Túnez & $\begin{array}{l}27 \text { de enero } \\
\text { de } 1980\end{array}$ & $\begin{array}{l}\text { Ayuda de Francia para hacer } \\
\text { frente a un intento de Libia de } \\
\text { tomar la ciudad de Gafsa }\end{array}$ & $\mathrm{X}$ & \\
\hline
\end{tabular}


En comparación con las presidencias de De Gaulle y de Pompidou, durante la presidencia de Valery Giscard d'Estaing, Francia empezó a actuar de manera más intervencionista. Así, el cuadro sobre las intervenciones durante su mandato presenta una concentración de operaciones no clandestinas en un periodo corto (1977-1981), correspondiente al resurgimiento de fuertes tensiones Este-Oeste a nivel mundial. En estos años, el intervencionismo francés dejó ver una imbricación entre los intereses tradicionales de Francia en su rol de protector regionaly los intereses del bloque occidental a favor de la contención de la influencia soviética. ${ }^{55}$ Con sus intervenciones en Zaire, Chad o en la República Centroafricana, el gobierno francés quiso hacer frente a la influencia de los soviéticos y sus aliados de la República Democrática Alemana, de Cuba y, sobre todo, de Libia. ${ }^{56}$

En este contexto, Francia actuó de manera menos solitaria y no solamente tuvo el apoyo de sus socios tradicionales, sino también el de ciertos países del Magreb y del Medio Oriente, en el seno de un grupo informal llamado "Safari club”, que se constituyó a mitad de la década de los años setenta para luchar militarmente en contra del comunismo. En el caso de Estados Unidos, la convergencia se instaló solamente tras el éxito militar de los soviéticos y los cubanos en contra de Somalia, en la región de Ogaden, en marzo de 1978. ${ }^{57}$

Si bien Francia pudo contar con varios aliados en su política africana, durante toda esa época de la nueva Guerra Fría en África, Europa se mantuvo al margen. ${ }^{58}$ Tras la segunda

55 P. Chaigneau, op.cit., p. 47. B. Bruyère-Ostells, "Outil militaire et politique africaine de la France depuis 1960: tableau historiographique et perspectives de recherche”, Relations internationales 2016/1, núm. 165, pp. 3-22.

${ }^{56}$ R. Aron, "La politique de la France", L'Express, 14-20 de marzo de 1981.

57 O. A. Westad, The Global Cold War: Third World Interventions and the Making of Our Times, Cambridge, University Press, 2005, p. 276.

58 N. Kinsey Powell, N., "La France, les États-Unis et la Force interafricaine au Zaïre (1978-1979)". Relations internationales, 150, núm. 2, (2012), pp. 71-83. Westad, op.cit., p. 276. 
intervención en el Shaba, el presidente francés intentó presentar sus intervenciones como parte de una acción europea, en una entrevista televisada, el 12 de abril de 1977.59 Sin embargo, en ausencia de una deliberación para la adopción de una posición común, y con la no participación de los otros países europeos en las operaciones francesas, su declaración no se ajustaba a la realidad política y militar. Además de eso, con Bélgica, el único socio europeo implicado en los asuntos africanos, seguía prevaleciendo la competencia sobre la cooperación. ${ }^{60}$

A pesar de lo anterior, la voluntad del presidente Giscard d'Estaing de presentar esas operaciones como "europeas", mostraba la creencia en que la existencia de un marco europeo legitimaría más el rol de protector regional ejercido por Francia. Esta actitud se explicaba por la voluntad del gobierno de responder a las críticas internas dado que, a pesar de la inscripción de las intervenciones francesas en el marco de la nueva Guerra Fría, éstas se percibían como nuevas operaciones neocolonialistas más que como operaciones anticomunistas. ${ }^{61}$

Del fin de la Guerra Fría al genocidio ruandés: hacia una europeización forzada del intervencionismo francés en África

Durante la campaña electoral de 1981, la política africana de Valéry Giscard d'Estaing estuvo en el centro de las críti-

${ }^{59}$ Conferencia de M. Valéry Giscard d'Estaing, 12 de abril de 1977.

${ }^{60}$ En una nota con fecha del 14 de mayo de 1979, René Journiac, asesor de V. Giscard d'Estaing para los asuntos africanos, informó el presidente que "los embajadores americano y belga se muestran muy críticos frente a la futura conferencia franco-africana de Kigali, consecuencia de las travesuras francesas". Nota de Réné Journiac para el presidente, 14 de mayo de 1979, AN, 5AG3/1204.

${ }^{61}$ J.P. Bat, "Les Diamants (de Bokassa) sont éternels. 'Pré carré' et guerre fraîche: la fabrique de la Françafrique". Afrique contemporaine, 246, núm. 2, (2013), pp. 127-148. 
cas de los partidarios del candidato del partido socialista, François Mitterrand. ${ }^{62}$ Sin embargo, tras su elección, este último asumió el papel de protector de los países del pré carré, descartando la posibilidad de revisar los acuerdos de cooperación militar.

\author{
Cuadro 3
}

Las intervenciones militares francesas en África bajo la presidencia de François Mitterrand (1981-1995)

\begin{tabular}{|c|c|c|c|}
\hline $\begin{array}{l}\text { País, nombre de } \\
\text { la operación y } \\
\text { periodo }\end{array}$ & Objetivo & $\begin{array}{l}\text { Participación } \\
\text { europea }\end{array}$ & $\begin{array}{l}\text { Otros aliados; resolución del } \\
\text { CSNU; operación de la ONU }\end{array}$ \\
\hline $\begin{array}{l}\text { Camerún, agosto } \\
\text { de } 1981\end{array}$ & $\begin{array}{l}\text { En el marco del litigio entre Ca- } \\
\text { merún y Nigeria para la penínsu- } \\
\text { la de Bakassi, Francia envía un } \\
\text { Transall y pone en alerta a sus } \\
\text { fuerzas en la región }\end{array}$ & X & \\
\hline $\begin{array}{l}\text { Chad } \\
\text { Operación Manta, } \\
9 \text { de agosto de } \\
1983-1 \text { de agosto } \\
\text { de } 1984\end{array}$ & $\begin{array}{l}\text { Despliegue de } 3500 \text { hombres } \\
\text { para disuadir a las fuerzas de } \\
\text { G. Oueddei de entrar en el sur } \\
\text { del Chad }\end{array}$ & $\mathrm{X}$ & \\
\hline $\begin{array}{l}\text { Chad } \\
\text { Operación } \\
\text { Épervier } \\
16 \text { de febrero de } \\
1986-1 \text { de agosto } \\
\text { de } 2014\end{array}$ & $\begin{array}{l}\text { Detener la ofensiva de las } \\
\text { fuerzas de G. Oueddei apoyadas } \\
\text { por Gadafi. } \\
\text { En el mismo tiempo, la opera- } \\
\text { ción "Trionyx" permite destruir } \\
\text { la pista aérea de Ouadi Doum }\end{array}$ & X & \\
\hline $\begin{array}{l}\text { República del } \\
\text { Congo } \\
\text { Septiembre de } \\
1986\end{array}$ & $\begin{array}{l}\text { Francia envía un avión de } \\
\text { transporte de tropas para ayudar } \\
\text { al presidente congolés Denis } \\
\text { Sassou-Nguesso, que enfrenta } \\
\text { protestas }\end{array}$ & $\mathrm{X}$ & \\
\hline
\end{tabular}

62 A. Diarra, La gauche française et l'Afrique subsaharienne: Colonisation, décolonisation, coopération (XIXè-XXè siècles), París, Karthala, 2014, pp. 31-91. 


\begin{tabular}{|c|c|c|c|}
\hline $\begin{array}{l}\text { Togo } \\
25 \text { de septiembre } \\
\text { de } 1986\end{array}$ & $\begin{array}{l}\text { Enfrentado a una ofensiva de } \\
\text { oponentes provenientes de Gha- } \\
\text { na, Gnassingbé Eyadéma recibe } \\
\text { la ayuda de } 200 \text { paracaidistas y } \\
\text { cinco "jaguares" }\end{array}$ & $\mathrm{X}$ & \\
\hline $\begin{array}{l}\text { Comores } \\
\text { Operación Oside } \\
5 \text { de diciembre } \\
\text { de } 1989-16 \text { de } \\
\text { diciembre } \\
\text { de } 1989\end{array}$ & $\begin{array}{l}\text { Poner fin a la toma de control } \\
\text { del país por los mercenarios de } \\
\text { Bob Denard, tras el asesinato del } \\
\text { presidente Ahmed Abdallah }\end{array}$ & $\mathrm{X}$ & \\
\hline \begin{tabular}{|l|} 
Gabón \\
Operación Requin \\
24 de mayo de \\
1990-29 de mayo \\
de 1990
\end{tabular} & $\begin{array}{l}\text { Francia interviene para pro- } \\
\text { teger a sus nacionales en Port } \\
\text { Gentil. Sin embargo, la opera- } \\
\text { ción permite también a las au- } \\
\text { toridades gabonesas retomar el } \\
\text { control de la ciudad }\end{array}$ & $\mathrm{X}$ & \\
\hline $\begin{array}{l}\text { Ruanda } \\
\text { Operación Noroit } \\
4 \text { de octubre de } \\
\text { 1990-15 de di- } \\
\text { ciembre de } 1993\end{array}$ & $\begin{array}{l}\text { Para detener las incursiones de las } \\
\text { fuerzas armadas del Frente Patrió- } \\
\text { tico Ruandés (FPR) desde Ugan- } \\
\text { da, Francia envía dos compañías } \\
\text { de paracaidistas ( } 300 \text { hombres) }\end{array}$ & $\begin{array}{l}\text { Cooperación } \\
\text { con Bélgica } \\
\text { (500 hom- } \\
\text { bres) }\end{array}$ & $\begin{array}{l}\text { - Zaire (3000 hombres). } \\
\text {-En diciembre de 1993, } \\
\text { establecimiento de la mi- } \\
\text { sión de las Naciones Uni- } \\
\text { das en Ruanda (MINUAR) }\end{array}$ \\
\hline $\begin{array}{l}\text { Somalia } \\
\text { Fuerza de inter- } \\
\text { vención unificada, } \\
\text { diciembre de } \\
\text { 1992-diciembre } \\
\text { de } 1993\end{array}$ & $\begin{array}{l}\text { Esta intervención humanitaria es } \\
\text { liderada por Estados Unidos, que } \\
\text { envía } 28000 \text { hombres. Francia } \\
\text { participa con } 3000 \text { soldados }\end{array}$ & $\begin{array}{l}\text { Bélgica, } \\
\text { Grecia, Italia, } \\
\text { Países Bajos, } \\
\text { Noruega, } \\
\text { Rumania, } \\
\text { Suecia }\end{array}$ & $\begin{array}{l}\text { Resolución núm. } 794 \text { del } \\
\text { CSNU, el } 3 \text { de diciembre } \\
\text { de } 1992\end{array}$ \\
\hline $\begin{array}{l}\text { Ruanda } \\
\text { Operación } \\
\text { Turquoise } \\
22 \text { de junio de } \\
\text { 1994-21 de agosto } \\
\text { de } 1994\end{array}$ & $\begin{array}{l}\text { Según la resolución } 929 \text { del } \\
\text { csnu: "Poner fin a las masacres } \\
\text { en todas partes donde sea posi- } \\
\text { ble, eventualmente con el uso } \\
\text { de la fuerza" }\end{array}$ & $\begin{array}{l}\text { Cobertura } \\
\text { satelital de la } \\
\text { UEO. }\end{array}$ & $\begin{array}{l}\text { - Francia envía } 1500 \text { sol- } \\
\text { dados y cuenta con la } \\
\text { participación de } 500 \text { sol- } \\
\text { dados africanos (Egipto, } \\
\text { Guinea Bissau, Egipto, } \\
\text { Mauritania, Níger, Sene- } \\
\text { gal y Chad) } \\
\text { - Resolución núm. } 929 \\
\text { del csNu el } 22 \text { de junio } \\
\text { de } 1994\end{array}$ \\
\hline
\end{tabular}


Si bien subsistía la duda sobre la voluntad del nuevo gobierno de aplicar los acuerdos de Defensa en los Estados del pré carré, Mitterrand pudo dar garantías a los mandatarios africanos desde agosto de 1981, interviniendo para apoyar a Camerún en la crisis con Nigeria. ${ }^{63}$ No obstante, Mitterrand buscó establecer una frontera clara entre la legítima protección hacia injerencias exteriores y el apoyo a regímenes frente a sus oposiciones internas. Según esta voluntad, no intervino después de los golpes de Estado en la RCA, el 1 de septiembre de 1981, y en Alto Volta, el 7 de noviembre de $1982 .{ }^{64}$

Sin embargo, el problema más espinoso para el gobierno francés seguía siendo el del Chad. En un primer momento, Mitterrand decidió apoyar al presidente de este país, Goukouni Oueddei, a pesar de su proximidad con Gadafi. ${ }^{65} \mathrm{Si}$ bien la retirada de las tropas libias en otoño justificó la decisión del presidente francés, su efecto inmediato fue provocar nuevos enfrentamientos entre las fuerzas de Goukouni Oueddei y las de su oponente, Hissène Habré. ${ }^{66}$ De este modo, cuando este último tomó la capital, N'Djamena, el 7 de junio de 1982, obligando a Oueddei a exiliarse, Mitterrand subrayó el carácter intraestatal del conflicto y estableció lazos de cooperación con Habré. Por el contrario, el gobierno francés no logró disuadir al coronel Gadafi de apoyar de nuevo la ofensiva de Oueddei, quien, gracias a la ayuda libia, retomó Faya Largeau el 24 de junio de 1983. En este contexto, los llamamientos de Estados Unidos y de gobiernos del pré carré, para que Francia asumiera su rol de protector regional, acabaron por convencer a Mitterrand de desplegar la

${ }^{63}$ P. Marchesin, "Mitterrand l'africain", Politique africaine, 58 (1995), p. 20.

${ }^{64}$ R. Dumas, La diplomatie sur le vif: dialogues avec Bertrand Badie et Gaïdz Minassian, París, Presses de Sciences Po, 2013, p. 71.

${ }^{65}$ R. Bruce St John, Libya and the United-States, Philadelphia, University of Pensilvania Press, 2002, p. 122.

${ }_{66}$ P. Favier, M. Martin-Roland, La décennie Mitterrand, t.3: Les défis, París, Points, 2016 [1996]. p. 345. 
operación "Manta", el 9 de agosto de 1983.67 En menos de tres años, Francia intervino de nuevo en Chad con las operaciones "Trionyx" y "Epervier" (véase cuadro 3).

Mientras que el periodo de cohabitación durante el gobierno de Jacques Chirac (1986-1988) estuvo marcado por el consenso para asumir el rol de protector, es el cambio del sistema internacional, con el fin de la Guerra Fría, lo que afectó la política africana de Francia. Con la desaparición de la Unión Soviética, Francia ya no podía legitimar su apoyo a regímenes no democráticos en nombre de la lucha contra el comunismo. En sus memorias, Hubert Védrine, el secretario general de la Presidencia de la República con Mitterrand, entre 1991 y 1995, reconoció la importancia del fin del "chantaje a la Unión soviética”, que le quitó a Francia su rol de agente anticomunista ${ }^{68}$ En este contexto, Benín constituyó el terreno de experimentación de los estándares de buena gobernanza. En este país, marcado por la crisis económica y la impopularidad del presidente Mathieu Kérékou en el poder desde 1972, Francia propuso una ayuda de 160 millones de francos a cambio del "abandono del partido único y que se convocara una conferencia nacional”. ${ }^{69} \mathrm{El}$ embajador francés en Benín tuvo un papel clave para convencer a Kérékou de adoptar el multipartidismo. ${ }^{70}$ Esta nueva política de Francia puso también de relieve una dinámica de adaptación al mayor poder del Banco Mundial, que se vio reflejada tanto a nivel de la política bilateral de Francia, como de la política europea. Lo anterior, debido a que el acuerdo de Lomé 3 en 1984 adoptó

${ }^{67}$ J. Attali, Verbatim, t. I, 1981-1986, París, Robert Laffont, 2011, [1993], pp. 463-564. A- Allam-Mi, Autour du Tchad en guerre: tractations politiques et diplomatiques, 1975-1990, París, L'Harmattan, 2015, pp. 151-153.

68 H. Védrine, Les mondes de François Mitterrand: à l'Elysée 1981-1995, París, Fayard, 1996, p. 243.

${ }^{69}$ G. Penne, Mémoires d'Afrique (1981-1998), París, Fayard, 1999, p. 346.

${ }^{70} \mathrm{M}$. Adamon, Le renouveau démocratique au Bénin, la conférence nationale des forces vives et la période de transition, París, L'Harmattan, 1994, pp. 22-24; 82. 
las normas del Banco Mundial sobre la condicionalidad económica y el ajuste estructural. ${ }^{71}$

Tras la experiencia en Benín, el modelo de la conferencia nacional se difundió rápidamente en los países del pré carré, en particular después del discurso de Mitterrand en la Baule el 20 de junio de 1990, en el que proclamó que Francia condicionaría su ayuda a la adopción de los estándares de la democracia. ${ }^{72}$ Este cambio de reglas en la relación clientelista estaba directamente relacionado con el contexto internacional y reflejó la búsqueda de una nueva credibilidad para la política africana de Francia. ${ }^{73}$

Si bien la adopción de un nuevo rol, que puede identificarse según la tipología de Holsti como el de "defensor de un sistema de valores" mediante la promoción de la democracia, compensó desde un punto de vista ético la pérdida del rol de agente anticomunista, dado que este último no fue relevante para decidir sobre las operaciones militares a desplegar. ${ }^{74}$ Así, Francia se negó a intervenir con la fuerza cuando Joseph Kokou Koffigoh, antiguo presidente de la Liga Togolesa de los Derechos Humanos, nombrado primer ministro de la transición democrática, fue encarcelado por el presidente Eyadéma Gnassingbé. ${ }^{75}$ En esta ocasión, el gobierno recordó

${ }^{71}$ J.P. Cling, "La Banque mondiale, entre transformations et résilience”, Critique Internationale, 2011/4, núm. 53, pp. 43-65. En el nivel de la política bilateral, el gobierno francés adoptó, desde 1993, un principio de condicionamiento de su ayuda a la adopción, de los Estados africanos, de programas económicos que se beneficien del apoyo del FMI y del Banco Mundial. A esta evolución se le conoce como la "doctrina Balladur", por el nombre del primer ministro francés, Édouard Balladur, entre 1993 y 1995.

${ }^{72} \mathrm{~W}$. Omitoogun y K. Onigu-Otite, Tise national conference as a model for democratic transition, Benin and Nigeria, IFRA, Ibadan, 1996, p. 2. E. Orsenna, "Quinze ans après", Lettre de l'IFM, 2005, p. 12.

${ }^{73} \mathrm{D}$. Ambrosetti, Normes et rivalités diplomatiques à l'ONU. Le Conseil de sécurité en audience, Bruselas, P.I.E. Peter Lang, 2009.

${ }^{74}$ J.P. Bat, op.cit., p. 514.

75 J. Heilbrunn y W. M. Toulabor, "Une si petite démocratisation pour le Togo”, Politique africaine, núm. 58 (1995), pp. 85-100. 
que solamente un jefe de Estado podía activar los acuerdos de defensa. Finalmente, la adopción del rol de "defensor de un sistema de valores" se limitó a una aplicación más restrictiva del rol de protector regional. ${ }^{76}$ De este modo, por haber rechazado cualquier consideración del criterio democrático en la relación clientelista franco-africana, los mandatarios de Chad y de Malí, Hissène Habré y Moussa Traoré, facilitaron la inacción de Francia durante su derrocamiento (1 de diciembre de 1990 y 26 de marzo de 1991).

Sin embargo, en estos dos casos, si Francia no intervino fue también porque los cambios de mandatario no ponían en tela de juicio las buenas relaciones con estos países. ${ }^{77}$ Por el contrario, cuando el régimen de Omar Bongo se encontró en dificultades en 1991, Francia no dudó en desplegar la operación "Requin" en Gabón. ${ }^{78}$ De la misma manera, en octubre de 1990, Mitterrand aceptó prestar asistencia al presidente ruandés Juvénal Habyarimana en virtud de los acuerdos franco-ruandeses de 1983 (véase cuadro 3). Si bien la misión tenía como objetivo oficial asegurar la seguridad de los nacionales franceses, la llegada de las fuerzas francesas permitió bloquear la invasión del Frente Patriótico Ruandés (FPR) ${ }^{79}$

Para el presidente francés, el carácter exterior de la agresión del FPR (apoyada por Uganda y los servicios de inteligencia de Libia), justificaba la activación de los acuerdos de defensa, la entrega de materiales militares y la intervención militar. ${ }^{80}$ Sin embargo, el hecho de que el conflicto estuviera ligado a la voluntad de los tutsi refugiados en Uganda de volver a Ruanda, creó una ambigüedad en la operación

76 R. Dumas (2013), op.cit., p. 178.

77 J. Foccart, (1997), op.cit., p. 321.

${ }^{78} \mathrm{~J}$. de Lespinois, L'armée de terre française: de la défense du sanctuaire à la projection, París, L'Harmattan, vol. 2, 2001, p. 793.

79 B. Collombat, B., Au nom de la France: guerres secrètes au Rwanda, París, La Découverte, 2014, pp. 23-25.

${ }^{80}$ P. Favier y M. Martin-Roland, La décennie Mitterrand, t.1, Les ruptures, París, Points, 2016 [1990], p. 438. 
francesa, que podía parecer a la vez como una intervención para hacer frente a una agresión exterior y como una política de injerencia en los asuntos ruandeses. En este contexto, el gobierno francés siguió una doble política que consistía en prestar asistencia al régimen ruandés con motivo de las incursiones puntuales del FPR y, al mismo tiempo, presionar al presidente Habyarimana para que llevase a cabo negociaciones.

Si bien Francia supervisó la conclusión de los acuerdos de Arusha el 21 de agosto de 1993, el atentado en contra del presidente Juvénal Habyarimana, el 6 de abril de 1994, provocó, por una parte, el principio del genocidio contra los tutsis y, por otra, una ofensiva victoriosa del FPR. En este contexto, Francia intervino en junio con la operación "Turquoise", tras haber obtenido una resolución del Consejo de Seguridad de la onu que la permitía. En esta ocasión, el ministro de Defensa francés, François Léotard, no logró convencer a su homólogo alemán, Volker Ruhe, para permitir una participación del Eurocuerpo y solamente pudo contar con una asistencia satelital de la UEO. Por el contrario, la UE tomó posición respecto a Ruanda solamente seis meses después del genocidio, pidiendo el retorno de los refugiados de las fronteras del país. ${ }^{81}$

La ausencia de una respuesta común en el caso de Ruanda reflejó el poco impacto que había tenido la creación de la política común, exterior y de seguridad (PESC) de la Unión Europea con ocasión del tratado de Maastricht, sobre la elaboración de una política común en África.

81 Wilde d'Estmael, T., “L’Union européenne et la résolution des conflits dans Remacle”, en Eric. V.B. Rosoux, L. Saur, L'Afrique des Grands Lac: des conflits à la paix? (coloquio organizado en noviembre de 2003 en Bruselas por Chaire Bernheim Paix y la la ciudadanía de l'ULB, el Centre d'étude des crises et des conflits internationaux de l'UCL, CECRI y el Centre de recherche en science politique des FUSL), Bruselas, PIE-P. Lang, 2007, pp. 189-202. 


\section{UNA EUROPEIZACIÓN CIRCUNSGRITA}

Debilitada con la triple ruptura de 1994: funeral del presidente marfileño Félix Houphouët-Boigny, devaluación del franco de la comunidad financiera africana (CFA) y, sobre todo, acusaciones de complicidad en el genocidio ruandés por su apoyo militar al régimen de Habyarimana y las ambigüedades de su acción durante el genocidio, Francia tuvo que buscar nuevas modalidades para mantener su rol de protector regional en su pré carré. ${ }^{82}$ Los años de cohabitación entre Jacques Chirac, electo presidente en 1995, y Lionel Jospin, primer ministro socialista nombrado tras las elecciones legislativas de 1997, estuvieron marcados por la fusión del Ministerio de la Cooperación con el Ministerio de los Asuntos Exteriores, la disminución de la presencia militar en África y el lanzamiento del programa RECAMP (Refuerzo de las capacidades africanas de mantenimiento de la paz), destinado a preparar los ejércitos africanos para hacerse cargo de la seguridad del continente. ${ }^{83}$ Más allá de la triple crisis de 1994, esta evolución de la política de Francia en África respondía también a la evolución de la pos Guerra Fría y al ambiente favorable para una regionalización de la resolución de las crisis tras los fracasos de la onU en Somalia y Ruanda. ${ }^{84}$ En este contexto, en ocasión de la adopción de la política europea de seguridad y defensa (PESD) en el Tratado de Niza de 2001, Francia pudo proceder a una europeización de su intervencionismo militar. Esta respuesta correspondía a la evolución general de la diplomacia francesa

${ }^{82}$ Y. Gounin, La France en Afrique. Le combat des Anciens et des Modernes, Bruselas, De Boeck Supérieur, 2009.

83 R. Banegas y R. Marchal, "La Politique africaine: stratégie d'impuissance ou impasses d'une politique d'indécision, en C. Lequesne y M. Vaïsse (dirs.), La Politique étrangère de Jacques Chirac, París, Riveneuve, 2013, pp. 179-198.

${ }^{84}$ B. B. Ghali, "Supplement to an Agenda for Peace: Position Paper of the Secretary General on the Occasion of the Fiftieth Anniversary of the United Nations", UN Document A/ 50/60-S/1995/1, 3 de enero de 1995 . 
después de la Guerra Fría, con la adopción de dos "valores identitarios": la construcción europea y el apoyo y participación en las instituciones internacionales. ${ }^{85}$

\section{Cuadro 4}

Las intervenciones militares francesas en África bajo la presidencia de Jacques Chirac (1995-2007) y de Nicolas Sarkozy (2007-2012)

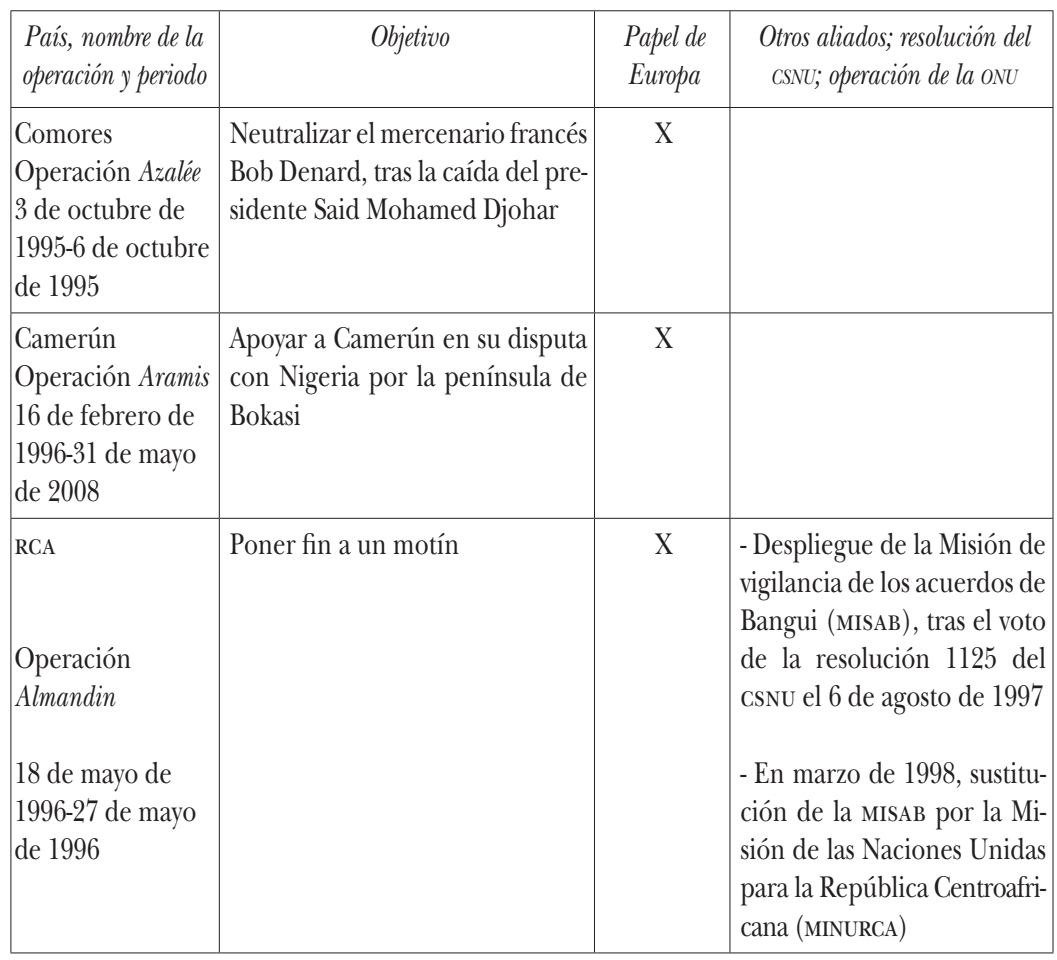

${ }^{85}$ A. Macleod, "L'approche constructiviste de la politique étrangere", en Frédéric Charillon (dir), Politique étrangère: nouveaux regards, París, Presses de Sciences Po, 2002. 


\begin{tabular}{|c|c|c|c|}
\hline $\begin{array}{l}\text { Costa de Marfil } \\
\text { Operación Licorne } \\
22 \text { de septiembre } \\
\text { de } 2002-21 \text { de } \\
\text { enero de } 2015\end{array}$ & $\begin{array}{l}\text { En 2002, intervención de } 5000 \\
\text { soldados franceses que se inter- } \\
\text { ponen entre las fuerzas de Costa } \\
\text { de Marfil y las fuerzas de la rebe- } \\
\text { lión del Norte } \\
\text { Abril de 2011: intervención de } \\
\text { la operación Licorne y de la onU } \\
\text { para permitir la detención de } \\
\text { Laurent Gbagbo, que se negaba } \\
\text { a reconocer la victoria electoral } \\
\text { de Alassane Ouattara }\end{array}$ & $\mathrm{X}$ & $\begin{array}{l}\text { - La operación Licorne es au- } \\
\text { torizada por la resolución } \\
1464 \text { del CSNU, el } 4 \text { de fe- } \\
\text { brero de } 2003 \\
\text { - En marzo de 2003, desplie- } \\
\text { gue de los cascos blancos } \\
\text { de la CEDEAo (operación } \\
\text { ECOForCE). } \\
\text { - } 4 \text { de abril de 2004: pasaje } \\
\text { de la fuerza de la CEDEAO } \\
\text { bajo mandato de la ONU } \\
\text { con el establecimiento de la } \\
\text { United Nations Operation } \\
\text { in Côte d'Ivoire (onUCI) } \\
\text { - Resolución } 1975 \text { del } 30 \text { de } \\
\text { marzo de } 2011 \text { adoptada en } \\
\text { el marco de la Responsabili- } \\
\text { dad de Proteger (R2P) }\end{array}$ \\
\hline $\begin{array}{l}\text { RCA } \\
\text { Operación Boalis } \\
\text { Octubre de } \\
\text { 2002-diciembre } \\
\text { de } 2013\end{array}$ & $\begin{array}{l}\text { Operación militar para apoyar } \\
\text { el establecimiento de la Fuerza } \\
\text { Multinacional en la República } \\
\text { Centroafricana (FOMUC) }\end{array}$ & $\mathrm{X}$ & $\begin{array}{l}\text { Despliegue de la FOMUc por } \\
\text { la Comunidad Económica y } \\
\text { Monetaria de África Central } \\
\text { (CEMAC) }\end{array}$ \\
\hline $\begin{array}{l}\text { RDC } \\
\text { Operación Artémis } \\
6 \text { de junio de } \\
2003-6 \text { de } \\
\text { septiembre de } \\
2003\end{array}$ & $\begin{array}{l}\text { - Despliegue de } 1400 \text { soldados } \\
\text { ( } 90 \% \text { franceses) para restablecer } \\
\text { la seguridad en la provincia del } \\
\text { Ituri }\end{array}$ & $\begin{array}{l}\text { Operación } \\
\text { en el } \\
\text { marco de } \\
\text { la PESD }\end{array}$ & $\begin{array}{l}\text { - Resolución núm. } 1484 \text { del } \\
\text { csNu el } 30 \text { de mayo de } 2003 \\
\text { - Presencia de Artemis en la } \\
\text { concertación con la Misión } \\
\text { de las Naciones Unidas en } \\
\text { la República Democrática } \\
\text { del Congo (MONUC) }\end{array}$ \\
\hline $\begin{array}{l}\text { RDC } \\
\text { Operación } \\
\text { EUFOR-RDC } \\
28 \text { de marzo de } \\
2006-18 \text { de abril } \\
\text { de } 2006\end{array}$ & $\begin{array}{l}\text { Garantizar el éxito del proceso } \\
\text { electoral }\end{array}$ & $\begin{array}{l}\text { Operación } \\
\text { en el } \\
\text { marco de } \\
\text { la PESD }\end{array}$ & $\begin{array}{l}\text { - Resolución núm. } 6698 \text { del } \\
\text { cSNU el } 25 \text { de abril de } 2006 \\
\text { - Misión desplegada de mane- } \\
\text { ra simultánea con la MONUC } \\
\text { (noviembre de 1999-junio de } \\
\text { 2010) }\end{array}$ \\
\hline
\end{tabular}




\begin{tabular}{|c|c|c|c|}
\hline $\begin{array}{l}\text { Somalia } \\
\text { Operación Alcyon } \\
\text { y Operación EUNA- } \\
\text { VFOR Atalante } \\
\text { desde el } 10 \text { de no- } \\
\text { viembre de } 2008\end{array}$ & 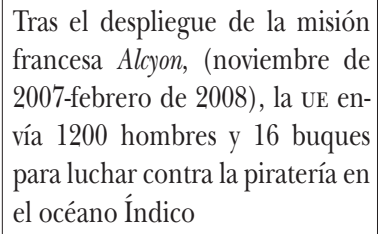 & $\begin{array}{l}\text { Operación } \\
\text { en el } \\
\text { marco de } \\
\text { la PESD }\end{array}$ & $\begin{array}{l}\text { Resolución } 1851 \text { del cSNU el } \\
16 \text { de diciembre de } 2008\end{array}$ \\
\hline $\begin{array}{l}\text { Chad } \\
1 \text { de febrero de } \\
2008\end{array}$ & $\begin{array}{l}\text { Intervención de las fuerzas espe- } \\
\text { ciales francesas para impedir la } \\
\text { toma de la capital por los rebel- } \\
\text { des de la Unión de Fuerzas para } \\
\text { la Democracia y el Desarrollo } \\
\text { (UFDD) apoyados por Sudán }\end{array}$ & $X$ & \\
\hline $\begin{array}{l}\text { Yibuti } \\
\text { Junio de } 2008\end{array}$ & $\begin{array}{l}\text { Apoyo logístico a Yibuti en su } \\
\text { conflicto con Eritrea }\end{array}$ & $X$ & \\
\hline $\begin{array}{l}\text { Chad } \\
\text { Operación } \\
\text { Chad/RCA } 28 \text { de } \\
\text { enero de } 2008-15 \\
\text { de marzo de } 2009\end{array}$ & $\begin{array}{l}\text { Con } 2100 \text { soldados sobre } 3700, \\
\text { Francia lidera la operación que } \\
\text { tiene como objetivo oficial pro- } \\
\text { teger los campos de refugiados } \\
\text { procedentes de Darfur }\end{array}$ & 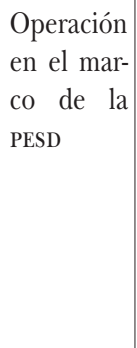 & $\begin{array}{l}\text { - Resolución núm. } 1778 \text { del } \\
\text { CSNU el } 25 \text { de septiembre de } \\
2007 \\
\text { - Reemplazo progresivo de } \\
\text { la operación europea por la } \\
\text { Misión de las Naciones Uni- } \\
\text { das en la República Centro- } \\
\text { africana (MINURCAT) }\end{array}$ \\
\hline
\end{tabular}

a $N$. del E. En 2005, los miembros de la Organización de las Naciones Unidas aprobaron por unanimidad la doctrina de la Responsabilidad de Proteger ( RdP o R2P por sus siglas en inglés), "diseñada para actuar colectivamente con el fin de poner coto a los que desde entonces vienen siendo calificados como 'crímenes atroces'”, cuyos antecedentes se remontan de manera más reciente al genocidio en Ruanda y, posteriormente, en Serbia. Con información de Emilio Menéndez del Valle, "Responsabilidad de proteger: la onU en acción”, s/1, Real Instituto Elcano, 15 de febrero de 2016.

LAS PRIMERAS OPERACIONES MILITARES DE LA UE EN ÁFRICA

Tras un golpe de Estado en Costa de Marfil en contra de Henri Konan Bédié, el 24 de diciembre de 1999, el contexto de la cohabitación obstaculizó una intervención de Francia dado que el primer ministro, Lionel Jospin, señaló al presidente Jacques Chirac su oposición a la aplicación de los acuerdos 
de defensa. Sin embargo, esa decisión simbolizó también un fuerte debilitamiento del rol de Francia como protector del pré carré. En esta época, en razón de los fracasos de las operaciones de mantenimiento de la paz de la onU en Ruanda (MINUAR) y en Somalia (ONUSOM y ONUSOM 2), la africanización de la resolución de las crisis en el marco de la Unión Africana y de las organizaciones subregionales, como la Comunidad Económica de Estados de África Occidental (CEDEAO), se presentaba como la respuesta promovida a nivel de las organizaciones africanas, así como de las grandes potencias, como Estados Unidos. ${ }^{86}$

En este nuevo entorno, cuando Jacques Chirac decidió finalmente lanzar una intervención en Costa de Marfil en septiembre de 2002, quiso actuar en concertación con la CEDEAO. Del mismo modo, la intervención de Francia tenía como objetivo favorecer una solución concertada entre las dos partes en vez de apoyar al gobierno. ${ }^{87}$ En África central, durante 1996, Francia intervino en la República Centroafricana para poner fin a un motín. Sin embargo, durante la cumbre franco-africana de diciembre de 1996, pidió a sus socios que reemplazaran su presencia con el objetivo de proceder a una africanización de la resolución del conflicto.

Si bien Francia dio prioridad a una mayor participación de los países africanos y de la onU en el África de los grandes lagos, donde estaba más debilitada, también empezó a apostar por una europeización de su política. Durante un primer

${ }^{86}$ G. R. Olsen, "The ambiguity of US foreign policy towards Africa", Third World Quarterly, 38, núm. 9 (2017), pp. 2097-2112. En el marco de la adopción de una Arquitectura africana de paz y seguridad, la Unión africana lanzó su primera operación de mantenimiento de la paz en Burundi en octubre de 2003, con el despliegue de una fuerza de 2700 militares. A. Augé, "Les soldats de la paix en afrique subsaharienne. Entre action militaire et logique politique", Guerres mondiales et conflits contemporains, vol. 229, núm. 1 (2008), pp. 43-53.

${ }^{87} \mathrm{~S}$. Smith, "La politique d'engagement de la France à l'épreuve de la Côte d'Ivoire", Politique africaine, vol. 89, núm. 1 (2003), pp. 112-126. H. Sada, "Le conflit ivoirien: enjeux régionaux et maintien de la paix en Afrique", Politique étrangère, núm. 2 (2003), p.p. 321-334. 
tiempo, para hacer frente a la ofensiva del oponente Laurent-Désiré Kabila, apoyado por Uganda y Ruanda, los países de la UE nombraron un enviado especial, sin que por ello se hubiesen puesto de acuerdo para desplegar una misión humanitaria con la Unión Europea Occidental (UEO). ${ }^{88}$ En razón de la oposición de sus socios europeos y de Estados Unidos a toda operación que hubiera podido ayudar al presidente Mobutu Sese Seko, Francia dejó a Kabila tomar el poder en mayo de 1997. ${ }^{89}$ Finalmente, en 2003 los miembros de la UE se pusieron de acuerdo para lanzar una primera intervención militar en África con la operación Artemis en la RDC. ${ }^{90}$ Esta operación fue permitida por los avances en materia de defensa europea desde la Declaración franco-británica de Saint-Malo, en diciembre de 1998, hasta la adopción definitiva de la política europea de seguridad y defensa (PESD) en 2001 con el Tratado de Niza.

Sin embargo, estos avances en la construcción de una ambición europea en materia de defensa estuvieron ligados principalmente al contexto de las guerras en los Balcanes y a las relaciones entre Europa y la OTAN. ${ }^{91}$ Por su parte, la operación en la RDC respondía a otras lógicas, en la medida en

${ }^{88}$ L. Davis, "Make do, or mend? EU security provision in complex conflicts: the Democratic Republic of Congo", European Security, 24, núm. 1 (2015), pp. 101-119. T. Wilde d'Estmael, op.cit. N. del E. La Unión Europea Occidental (UeO) fue una organización europea de defensa y seguridad, creada con base en los Tratados de Bruselas en 1948, que dejó oficialmente de existir en 2011. No debe confundirse con la Unión Europea.

${ }^{89} \mathrm{~S}$. Perrot, "Les nouveaux interventionnismes militaires africains. Une redéfinition des conditions de la puissance au sud du Sahara", Politique africaine, 98, núm. 2 (2005), pp. 111-130.

${ }^{90}$ Wilde d'Estmael, op.cit.

${ }^{91}$ R. J. Art, "Europe hedges its security bets", en T.V. Paul, J.J. Wirtz y M. Fortmann (eds.), Balance of power: theory and practice in the 21st century, Stanford, University Press, 2004, pp. 179-213. B. Posen, "European Union security and defence policy: response to unipolarity?", Security studies, 15, núm. 2 (2006), pp. 149-186. M. Weiss, "Transaction costs and the establishment of the European security and defense policy", Security studies, 21, núm. 4 (2012), pp. 654-682. 
que la OTAN nunca tuvo un papel importante en África. ${ }^{92}$ Así, al contrario de lo que pasó con la misión en Macedonia, primera operación exterior de la UE en el marco de la PESD, la operación Artemis no se inscribió en el marco de los acuerdos de Berlín+ firmados con la OTAN el 16 de diciembre de 2002. De la misma manera, contrariamente a la operación en Macedonia y de la operación Eufor Althea en Bosnia, es Francia quien ocupó el lugar de Estado marco. ${ }^{93}$ La presencia de 1639 soldados franceses dio a la operación Artemis el aspecto de europeización a una operación francesa. ${ }^{94}$

Para entender cómo la dinámica a favor de una Europa de la defensa estuvo orientada hacia el continente africano, es necesario subrayar el acercamiento bilateral entre Francia y el Reino Unido. Desde la declaración de SaintMalo del 4 de diciembre de 1998, los dos países acordaron dejar de lado su rivalidad en el continente africano para hacer frente a desafíos comunes: apoyar la africanización de la resolución de las crisis; mantener una influencia con medios reducidos; hacer frente a la competencia con nuevas potencias y, finalmente, reafirmar la legitimidad de su puesto como miembros permanentes del Consejo de Seguridad de las Naciones Unidas mediante un papel activo en el continente africano. ${ }^{95}$

En este contexto, la guerra en la RDC, donde actuaban países angloparlantes y francohablantes de África, constituyó un terreno privilegiado para una actuación de la UE. ${ }^{96}$ Así, gracias a este entendimiento franco-británico se consiguió

92 P. Haroche, "Interdependence, asymmetric crises, and European defence cooperation”, European Security, 26, núm. 2 (2017), pp. 226-252.

93 C. Gegout, art. cit. N. Bagayoko, "L’opération Artémis, un tournant pour la politique européenne de sécurité et de défense?”, Afrique contemporaine, núm. 209 (2004), pp. 101-116.

94 N.I.M Nováky, "Deploying EU military crisis management operations: a collective action perspective”, European Security”, 24, núm. 4 (2014), pp. 491-508.

95 T. Chafer y G. Cumming, art.cit.

${ }^{96}$ Haroche, art.cit. 
superar las reticencias de Alemania. ${ }^{97}$ Durante los años siguientes, la presencia de la UE en la RDC se prorrogó a través dos operaciones civiles: Eupol RDC en 2004 y Eusec RDC en 2005. En 2006, a raíz de la adopción en 2005 de una estrategia de la UE para África, una nueva operación militar nombrada Eufor fue desplegada en Kinshasa, en ocasión de las elecciones presidenciales. Esta vez, los dirigentes franceses lograron obtener una importante participación de Alemania. ${ }^{98}$ Finalmente, gracias a esas operaciones, Francia pudo seguir actuando política y militarmente en esa región en un marco colectivo, que podía matizar su rol de protector regional. ${ }^{99}$

\section{LOS LÍMITES DEL INTERVENCIONISMO EUROPEO}

Si bien es cierto que Francia es, con el Reino Unido, el actor que tiene el mayor potencial político-militar en la UE, no puede imponer los objetivos de su política de seguridad a los otros miembros con facilidad. La dificultad para obtener una acción de la uE viene de la necesidad de identificar intereses comunes. ${ }^{100}$ Desde este punto de vista, la operación Artemis fue el resultado de condiciones extraordinarias: voluntad de europeizar de Francia; ${ }^{101}$ convergencia de interés puntual

${ }^{97}$ O. Schmitt, "Strategic Users of Culture: German Decisions for Military Action”, Contemporary Security Policy, 33, núm. 1 (2012), pp. 59-81.

${ }^{98}$ K. Brummer, "The Reluctant Peacekeeper: Governmental Politics and Germany's Participation in EUFOR RD Congo", Foreign Policy Analysis (2012), pp. 1743-859.

99 S. Kingah y L. Van Langenhove, "Determinants of a regional organization's role in peace and security: the African Union and the European Union compared", South African Journal of International Affairs, 19, núm. 2 (2012), pp. 201-222.

${ }^{100}$ S. Keukeleire y J. MacNaughtan, op.cit. T. Dyson, "The Material Roots of European Strategy: Beyond Culture and Values", Contemporary Security Policy, 34, núm. 3 (2013), pp. 419-445.

${ }^{101}$ Gegout, op.cit. 
entre Francia y el Reino Unido; convergencia con Bélgica; ${ }^{102}$ apertura para un regateo con Alemania; ${ }^{103}$ y voluntad del alto representante de la UE para los asuntos exteriores, Javier Solana, de concretar la estrategia europea de seguridad adoptada en 2003. ${ }^{104}$ Tras las operaciones Artemis y Eufor RDC, la UE ya no desempeñó un papel central en la RDC, en particular después del fracaso de los acuerdos de Goma firmados en 2008. Así, Francia no pudo convencer a sus socios de desplegar una misión Artemis $2 .{ }^{105}$

En otros casos, como el de Costa de Marfil, los dirigentes franceses privilegiaron la búsqueda de apoyo de la onu y de la CEDEAO para legitimar su intervencionismo, en vez de una participación europea. Sin embargo, en 2008, Francia logró de nuevo obtener el despliegue de dos operaciones europeas en África: una marítima en las costas de Somalia (EUNAVFor Somalia), afuera de su pré carré tradicional, y una operación en Chad y la República Centroafricana (EUFOR Chad-RCA). En los dos casos, Francia desempeñó una función directiva.

En el primero, después de una operación unilateral denominada Alcyon, Francia logró convencer al Reino Unido de desplegar una intervención europea diferente a la ya desplegada por la OTAN. ${ }^{106} \mathrm{El}$ hecho de tener la presidencia del Consejo de la UE, entre julio y diciembre de 2008, facilitó sus trámites. ${ }^{107}$ De la misma manera, la coyuntura marcada por

102 S. Nasra, "Governance in EU foreign policy: exploring small state influence", Journal of European Public Policy, 18, núm. 2 (2011), pp. 164-180. 103 Haroche, art.cit.

104 B. Nivet, "Du laboratoire au miroir: quand l'Afrique subsaharienne construit l'Europe stratégique”, Politique africaine, vol. 127, núm. 3 (2012), pp. 135-153.

105 Davis, L., art. cit.

106 Nováky, art. cit. M. Riddervold, "New threats-different response: EU and NATO and Somali piracy”, European Security, 23, núm. 4 (2014), pp. 546-564.

${ }^{107}$ N. Hynek, "EU crisis management after the Lisbon Treaty: civil-military coordination and the future of the EU OHQ", European security, 20, núm. 1 (2011), pp. 81-102. F.M. Häge, "The scheduling power of the EU Council Presidency", Journal of European Public Policy, 24, núm. 5 (2016), pp. 695-713. 
el retorno de Francia en el mando integrado de la oTAN facilitó el entendimiento con el Reino Unido, que también tomó en cuenta la necesidad de Alemania de actuar en el marco de la UE en vez de la OTAN, por razones constitucionales. ${ }^{108}$

En el segundo caso, la misión desplegada con motivos humanitarios para proteger los campos de refugiados de Darfur también se inscribió en el marco de la protección acordada por Francia al régimen de Idris Deby en Chad. ${ }^{109} \mathrm{Si}$ bien Francia logró imponer esa misión, sus socios no aceptaron la participación de los battle groups y se negaron a aplicar el plan Athéna de financiamiento colectivo. ${ }^{110}$ Además, esa operación provocó un sentimiento de instrumentalización, en particular de Alemania. Así, tras la misión Eufor-Tchad, la posibilidad para Francia de poder apoyarse sobre la UE para sus operaciones en África se vio limitada. ${ }^{111}$ De este modo, el leve apoyo que Francia recibió durante su operación en Malí en 2013 tiene mucho que ver con la voluntad de los europeos de no ponerse al servicio de los intereses de Francia. Durante los meses anteriores a la operación, las autoridades francesas habían podido medir esas reticencias, en particular durante un Consejo de Ministros de la Defensa en Chipre el 26 y 27 de septiembre de 2012. ${ }^{112}$ Así, tras el lanzamiento de la operación Serval, el ministro de los Asuntos Exteriores lamentó la ausencia de movilización de los socios europeos de Francia en ocasión de una conferencia de prensa el 17 de enero y

108 Nováky, art.cit. Riddervold, art.cit.

109 Marchal, op.cit. Charbonneau, art. cit. Dijkstra, op.cit. G. Bono, "The EU's Military Operation in Chad and the Central African Republic: An Operation to Save Lives?”, Journal of intervention and statebuilding, 5, núm. 1 (2011), pp. 23-42.

110 Bono, art. cit.

111 Koepf, art.cit. J.Y. Haine, "The Failure of a European Strategic Culture - EUFOR CHAD: The Last of its Kind?”, Contemporary Security Policy, 32, núm. 3 (2011), pp. 582-603.

112 D. Revault d'Allones, Les Guerres du président, París, Éditions du Seuil, 2015, pp. 33-34. 
durante el Consejo de los Ministros de los Asuntos Exteriores del 11 de marzo de 2013. ${ }^{113}$

Si bien es cierto que la UE apoyó políticamente la intervención francesa, aceleró la ejecución de su estrategia para "el desarrollo y la seguridad del Sahel" adoptada en 2011, y nombró un enviado especial, su papel siguió siendo secundario, ya que no activó sus herramientas en materia de "poder duro", como los grupos de batallas. Frente a las solicitudes del gobierno francés, solamente pudo obtenerse el lanzamiento de una misión de formación de las fuerzas malienses: la UETM Malí. ${ }^{114}$ Gracias a esta operación, François Hollande pudo proclamar que los franceses no "estaban solos" en Malí, sino que habían sido los "primeros" en intervenir. ${ }^{115}$

Posteriormente a los atentados terroristas del 13 de noviembre de 2015 en París, ciertos socios europeos respondieron al llamado del presidente francés en favor de la aplicación del artículo 42.7 del tratado de Lisboa sobre la "solidaridad mutua en caso de una agresión armada en contra de un territorio miembro", con una mayor participación en la minusma y la UETM en Malí. De la misma manera, desde su elección, Emmanuel Macron hizo de los avances en materia de defensa europea uno de los principales objetivos de su política exterior. Así, tanto por razones políticas como económicas, la voluntad de europeización continuará vigente en los próximos años. Sin embargo, Francia no puede hacer caso omiso de los límites de la solidaridad de sus socios cuando se trata de participar en lógicas militares, que van más allá de la formación de las fuerzas

113 J.P. Chevénement y G. Larcher, Rapport d'information fait au nom de la commission des affaires étrangères, de la défense et des forces armées, núm. 513 (2012-2013).

114 B. Rouppert y A. Tisseron, "De la méditerranée au Sahel: la sécurité d'abord", en Abdennour Benantar, La sécurité en Méditerranée occidentale : face aux bouleversements au Maghreb et au Sahara, París, L'Harmattan, 2015, pp. 11-29.

115 Revault d'Allones, op. cit., p. 54. 
locales. ${ }^{116}$ Además, gracias al reconocimiento de la pertinencia de las acciones militares de Francia en Malí por la mayoría de los países africanos y por los miembros permanentes del Consejo de Seguridad de la onu, la voluntad de poner a la uE en el primer plano ya no es tan necesaria como antes. ${ }^{117}$ De hecho, la crisis maliense confirmó que después de los escollos del rol de protector de Francia en África, que empezaron con el fin de la Guerra Fría y culminaron con las intervenciones en Ruanda y en Costa de Marfil, en 1994 y 2002 respectivamente, Francia pudo asumir plenamente su rol de protector regional en nombre de la lucha en contra de grupos armados islamistas. El 1 de agosto de 2014, la transformación de la operación Serval en una operación denominada "Barkhane", de carácter regional, con 4000 hombres en cinco países del Sahel (Mauritania, Níger, Chad, Burkina Faso y Malí), confirmó la inscripción de la intervención francesa en el largo plazo. Mientras tanto, el apoyo de Francia a la puesta en marcha del G5 Sahel, coalición de los países donde actúa la operación Barkhane, confirmó la sinergia entre la acción de Francia y los mecanismos de africanización.

${ }^{116} \mathrm{D}$. Tull, La cooperation franco-allemande au Sahel: conséquences et perspectives du 'tournant africain' de l'Allemagne, Notes de recherche núm. 45, Irsem, 2017.

${ }^{117}$ En su acción en contra del terrorismo islamista, Francia puede contar en particular con el apoyo de Estados Unidos. La operación Serval se benefició de un apoyo en materia de inteligencia, observación (drones y aviones de reconocimiento), transporte aéreo estratégico (tres C-17) y de reaprovisionamiento en vuelo (tres KC 135) (Panon, 2016, p. 212). Además, Estados Unidos acordó un sobre especial de 50 millones de dólares para la operación Serval el 11 de febrero de 2013 y otro de 10 millones de dólares al momento del despliegue de la operación Barkhane (Kandel, 2014). 
Cuadro 5

\section{Las intervenciones militares francesas en África bajo las presidencias de François Hollande (2012-2017) y de Emmanuel Macron (desde 2017)}

\begin{tabular}{|c|c|c|c|}
\hline $\begin{array}{l}\text { País, nombre de la } \\
\text { operación y periodo }\end{array}$ & Objetivo & Papel de Europa & $\begin{array}{c}\text { Otros aliados; resolución } \\
\text { del cSNU; operación de } \\
\text { la ONU }\end{array}$ \\
\hline $\begin{array}{l}\text { Níger } \\
\text { Operación EUCAP } \\
\text { Sahel desde el } 17 \\
\text { de julio de } 2012\end{array}$ & $\begin{array}{l}\text { Formar las fuerzas de segu- } \\
\text { ridad nigerianas para luchar } \\
\text { contra el terrorismo y el cri- } \\
\text { men organizado }\end{array}$ & $\begin{array}{l}\text { Operación en } \\
\text { el marco de la } \\
\text { PCSD }^{\mathrm{a}}\end{array}$ & \\
\hline $\begin{array}{l}\text { Malí } \\
\text { Operación Serval } \\
20 \text { de diciembre de } \\
2012-15 \text { de julio de } \\
2014\end{array}$ & $\begin{array}{l}\text { Detener el avance de los gru- } \\
\text { pos terroristas }\end{array}$ & $\begin{array}{l}\text { En } 2015 \text { la UE } \\
\text { decidió poner en } \\
\text { marcha el Plan } \\
\text { de acción del } \\
\text { Sahel } 2015 .\end{array}$ & $\begin{array}{l}\text { Resolución } 2085 \text { del } 20 \\
\text { de diciembre de } 2012\end{array}$ \\
\hline $\begin{array}{l}\text { Malí } \\
\text { Operación EuTM } \\
\text { Malí desde el } 18 \text { de } \\
\text { febrero de } 2013\end{array}$ & $\begin{array}{l}\text { Ayudar a la formación y la } \\
\text { reorganización de las fuerzas } \\
\text { armadas de Malí }\end{array}$ & $\begin{array}{l}\text { Operación en } \\
\text { el marco de } \\
\text { la PCSD, con } \\
\text { participación del } \\
\text { Eurocuerpo }\end{array}$ & \\
\hline $\begin{array}{l}\text { RCA } \\
\text { Operación Sangaris } \\
5 \text { de diciembre de } \\
2013-31 \text { de octubre } \\
\text { de } 2016\end{array}$ & $\begin{array}{l}\text { Despliegue de hasta } 2500 \\
\text { hombres para poner fin a } \\
\text { los enfrentamientos entre los } \\
\text { musulmanes de la Seleka y las } \\
\text { milicias cristianas "antibalaka" }\end{array}$ & & $\begin{array}{l}\text { Resolución } 2127 \text { del } \\
\text { cSNu el } 12 \text { de mayo } \\
\text { de } 2013 \\
\text { Sangaris viene en } \\
\text { apoyo a la Misión In- } \\
\text { ternacional de Apoyo } \\
\text { a la República Centro- } \\
\text { africana con Liderazgo } \\
\text { africano (MISCA), } \\
\text { reemplazada por la } \\
\text { Misión Unidimensio- } \\
\text { nal Integrada de las } \\
\text { Naciones Unidas para } \\
\text { la Estabilización en la } \\
\text { República Centroafri- } \\
\text { cana (MINuSCA) desde } \\
\text { el } 10 \text { de abril de } 2014\end{array}$ \\
\hline
\end{tabular}




\begin{tabular}{|c|c|c|c|}
\hline $\begin{array}{l}\text { RCA } \\
\text { Operación EUTM } \\
\text { RCA } \\
\text { Desde el } 19 \text { de abril } \\
\text { de } 2016\end{array}$ & $\begin{array}{l}\text { Ayudar a la formación y re- } \\
\text { organización de las fuerzas } \\
\text { armadas de RCA }\end{array}$ & $\begin{array}{l}\text { Operación en el } \\
\text { marco de la PCSD }\end{array}$ & \\
\hline $\begin{array}{l}\text { Malí } \\
\text { Operación EucaP } \\
\text { Sahel Malí } \\
\text { Desde el } 15 \text { de abril } \\
\text { de } 2014\end{array}$ & $\begin{array}{l}\text { Operación civil de la UE para } \\
\text { apoyar las fuerzas de seguri- } \\
\text { dad internas de Malí }\end{array}$ & $\begin{array}{l}\text { Operación en el } \\
\text { marco de la PCSD }\end{array}$ & \\
\hline $\begin{array}{l}\text { Mauritania, Níger, } \\
\text { Chad, Burkina } \\
\text { Faso, Malí, } \\
\text { Operación } \\
\text { Barkhane } \\
\text { Desde el } 1 \text { de } \\
\text { agosto de } 2014\end{array}$ & $\begin{array}{l}\text { - Luchar contra los grupos } \\
\text { terroristas el Sahel } \\
\text { - Ésta reemplaza la operación } \\
\text { Serval en Malí y la operación } \\
\text { Épervier en Chad }\end{array}$ & & $\begin{array}{l}21 \text { de julio de } 2017, \\
\text { resolución núm. } 2359 \\
\text { sobre el despliegue de } \\
\text { la fuerza conjunta G5 } \\
\text { Sahel, formada por } \\
\text { Malí, Mauritania, Bur- } \\
\text { kina Faso, Chad, Níger } \\
\text { y lanzada oficialmente } \\
\text { el } 2 \text { de julio }\end{array}$ \\
\hline $\begin{array}{l}\text { Mar Mediterráneo } \\
\text { Operación Eunavfor } \\
\text { Med operación Sophia } \\
\text { Desde el } 22 \text { de } \\
\text { junio de } 2015\end{array}$ & & $\begin{array}{l}\text { Operación en el } \\
\text { marco de la PCSD }\end{array}$ & \\
\hline $\begin{array}{l}\text { Chad } \\
3 \text { a } 6 \text { de febrero de } \\
2019\end{array}$ & $\begin{array}{l}\text { Bombardeos en el Noreste } \\
\text { de Chad para hacer frente a } \\
\text { una incursión de la Unión de } \\
\text { las Fuerzas de la Resistencia } \\
\text { (uFR) desde Libia }\end{array}$ & & \\
\hline
\end{tabular}

a Después del Tratado de Lisboa de 2009, la política europea de seguridad y defensa (PESD) tomó el nombre de política común de seguridad y defensa (PCSD).

\section{Conclusión}

Desde la pérdida de su imperio colonial, los dirigentes franceses siempre buscaron apoyarse en el proyecto europeo para consolidar la relación estrecha que mantuvo Francia con sus antiguas colonias mediante la firma de acuerdos de 
cooperación. Si bien es cierto que, durante un primer tiempo privilegiaron el papel económico de la construcción europea, a partir de los años setenta quisieron dar una dimensión europea al intervencionismo militar en África. La europeización, que en principio fue retórica, paso a ser real con el fin de la Guerra Fría y la deslegitimación del papel protector de Francia, tras el genocidio en Ruanda.

El lanzamiento de operaciones militares y civiles de la UE en África franco-hablante, a partir de la operación Artemis en la República Democrática del Congo en 2003, pudo llevar a pensar en una posible "comunitarización" del intervencionismo francés en África. Sin embargo, sólo un número reducido de Estados tuvo una relevancia significativa en los procesos de decisión que llevaron al despliegue de las misiones europeas. Finalmente, en la medida en que nunca puede garantizarse este entendimiento entre los principales Estados, incluso con argumentos éticos, para Francia la uE aparece como una herramienta, entre otras, que puede movilizarse de manera puntual. Asimismo, a pesar del interés creciente de la UE por el continente africano, desde la adopción de una estrategia de la UE para África en 2005 y del "Joint Africa-EU Strategy" (JAES) en diciembre de 2007, ${ }^{118}$ las estrategias militares de Francia en África todavía ocasionan, por parte de los demás miembros, falta de interés o, en el peor de los casos, rechazo. ${ }^{119}$

El interés limitado de Alemania por África, la prioridad que dan los países de Europa del Este a las relaciones con Rusia y los resurgimientos de competencia con el Reino Unido y Bélgica son otros tantos obstáculos para una europeización del intervencionismo francés en África. ${ }^{120}$ A pesar del aumento de legitimidad conferido por una participación eu-

118 N. Bagayoko y M.V. Gibert, "The European Union in Africa: the linkage between security, governance and development from an institutional perspective”, The Journal of Development Studies, Taylor \& Francis (Routledge), 45, núm. 05 (2009), pp. 789-814.

119 G. Snyder, "The Security Dilemma in Alliance Politics", World Politics, 36, núm. 4 (1984), pp. 461-495.

${ }^{120}$ Haroche, art.cit. 
ropea, las dificultades de obtener un apoyo de sus socios y los límites de las capacidades de estos últimos se conjugan para disuadir a los dirigentes franceses de hacer de la UE el principal instrumento de su política africana. Finalmente, nada permite hablar de una posible transferencia del rol de protector regional de los regímenes africanos de Francia a la UE.

Por otro lado, si bien es cierto que la Ue se impuso como un actor en la resolución de los conflictos en África, su presencia se inscribe en el marco de una división del trabajo en el cual no tiene un papel de "poder duro". Mientras que la operación EUFOR Chad-RCA pudo haberse percibido como el indicio de un proceso de mutación de la PCSD de un poder civil a un poder militar, ${ }^{121}$ la crisis en Malí desmintió esa dinámica, confirmando en cambio la inclinación de la ue de no intervenir en casos militarmente complicados. ${ }^{122}$ Por el contrario, desde el punto de vista de los responsables franceses de la toma de decisiones, la crisis maliense confirmó la idoneidad del sistema de decisión a escala del Estado nación. En este sentido, durante un simposio sobre la democracia, el 6 de octubre de 2016, Hollande resaltó las ventajas de la Constitución francesa que le dieron la posibilidad de "actuar con rapidez". ${ }^{123}$ Así, a pesar de sus quejas en contra de los europeos, los dirigentes franceses no buscan compartir el poder de decisión, sino que se proponen obtener una solidaridad posterior a la decisión a nivel militar y, sobre todo, a nivel político-económico. De esta manera, las últimas intervenciones en Malí y en la RCA demuestran una di-

121 A. Treacher, "From Civilian Power to Military Actor: The EU's Resistable Transformation”, European Foreign Affairs Review, vol. 9, núm. 1 (2004), pp. 49-66. A. Rayroux, “Adaptation, projection, convergence: L'européanisation de la défense et l'intervention militaire EUFOR Tchad/ RCA”, Politique européenne, 34, núm. 2 (2011), pp. 201-230.

122 C. Gegout, "EU Conflict Management in Africa: The Limits of an International Actor”, Ethnopolitics, 8, núm. 3-4 (2010), pp. 403-415.

123 Intervención de François Hollande durante el simposio "rehacer la democracia” el 6 de octubre de 2016. Véase en Le Monde, 8 de octubre de 2016. 
visión del trabajo entre Francia, que entró primero en el terreno, y la uE, que intervino en segundo plano y actuó con operaciones limitadas, enfocadas en su mayoría en la formación de los ejércitos africanos, y se comprometió principalmente a nivel económico con la promesa de financiar hasta con 100 millones de euros la fuerza G5 Sahel en 2018. ${ }^{124}$ Por lo tanto, la evolución del intervencionismo francés en África confirma bien la renovación del rol de protector regional de Francia, asociado a una zona geográfica que corresponde en particular al espacio común del G5 Sahel y de la operación Barkhane. ${ }^{125}$

\section{Bibliografía}

Adamon, M., Le renouveau démocratique au Bénin, la conférence nationale des forces vives et la période de transition, París, Ed. L'Harmattan, 1994.

Allam-Mi, A., Autour du Tchad en guerre: tractations politiques et diplomatiques, 1975-1990, París, L'Harmattan, 2015.

Ambrosetti, D., Normes et rivalités diplomatiques à l'ONU. Le Conseil de sécurité en audience, Bruselas, P.I.E. Peter Lang, 2009.

AndrÉAni, G., "Le Concept de guerre contre le terrorisme fait-il le jeu des terroristes?” En G. Andréani (dir.) y P. Hasner, Justifier

124 N. Desgrais y S. Gouriellec, "Stratégies d'extraversion: Les défis de la construction de l'Architecture africaine de paix et de sécurité", Note de recherche stratégique, núm. 28, Irsem, 2016. Seau, "Sahel: l'UE mobilise 414 millions d'euros pour l'aide internationale", comunicado conjunto, 23 de febrero de 2018, https://eeas.europa.eu/headquarters/headquar ters-homepage/40762/node/40762_cs

125 G. Andréani, "Le Concept de guerre contre le terrorisme fait-il le jeu des terroristes?”, en G. Andréani (dir.) y P. Hasner, Justifier la guerre: de l'humanitaire au contre-terrorisme, París, Les Presses de SciencePo, 2005. J. P. Bat, "En Afrique, la France n'agit plus en solo, propos recueillis par Pascal Airault", Jeune Afrique, 4 de diciembre de 2013. F. Gaulme, "Intervenir au Mali: le retour du politique”, Etudes, 418, núm. 5 (2013). T. Chafer, "Hollande and Africa Policy", Modern E E Contemporary France, vol. 22, núm. 4 (2014), pp. 513-531. 
la guerre?: de l'humanitaire au contre-terrorisme, París, Les Presses de SciencePo, 2005.

Aron, R., "La politique de la France", L'Express, 14-20 de marzo de 1981.

ART, R.J., "Europe hedges its security bets", en T.V. Paul, J.J. Wirtz y Fortmann, M. (eds). Balance of power: theory and practice in the 21st century. Stanford, University Press, 2004, pp. 179-213.

Attali, J., Verbatim, t. I, 1981-1986, París, Robert Laffont, 2011 [1993].

Augé, A., "Les soldats de la paix en Afrique subsaharienne. Entre action militaire et logique politique", Guerres mondiales et conflits contemporains, vol. 229, núm. 1 (2008), pp. 43-53.

Badalassi, N., Adieu Yalta ? La France, la détente et les origines de la Conférence sur la Sécurité et la Coopération en Europe, 1965-1975 (tesis doctoral inédita), Universidad París III, 2011.

Bagayoko, N., "L'opération Artémis, un tournant pour la politique européenne de sécurité et de défense?”, Afrique contemporaine, 209 (2004), pp. 101-116.

Bagayoko, N. y M.V. Gibert, "The European Union in Africa: the linkage between security, governance and development from an institutional perspective", The Journal of Development Studies, Taylor \& Francis (Routledge), 45, núm. 05 (2009), pp. 789-814.

Banegas, R. y R. Marchal, "La Politique africaine : stratégie d'impuissance ou impasses d'une politique d'indécision", en C. Lequesne, M. Vaïsse (dir.), La Politique étrangère de Jacques Chirac, París, Riveneuve (2013), pp. 179-198.

BAT, J.P., Le Syndrome Foccart: la politique française en Afrique, de 1959 à nos jours, París, Gallimard, 2012.

BAt, J.P. "Les Diamants (de Bokassa) sont éternels. 'Pré carré' et guerre fraîche : la fabrique de la Françafrique", Afrique contemporaine, 246 núm. 2 (2013), pp. 127-148.

Bat, J.P., "En Afrique, la France n'agit plus en solo, propos recueillis par Pascal Airault", Jeune Afrique, 4 de diciembre de 2013.

BAt, J.P., La fabrique des 'barbouzes', París, Nouveau monde éditions, 2015. 
Biarnés, P. Les Français en Afrique noire: de Richelieu à Mitterrand: 350 ans de présence française au sud du Sahara, París, Armand Colin, 1987.

Bono, G., "The EU's Military Operation in Chad and the Central African Republic: An Operation to Save Lives?", Journal of intervention and statebuilding, 5, núm. 1 (2011), pp. 23-42.

Brummer, K., "The Reluctant Peacekeeper: Governmental Politics and Germany's Participation in EUFOR RD Congo", Foreign Policy Analysis (2012), pp. 1743-1859.

Bué, C., "La politique de développement de l'Union européenne: réformes et européanisation", Critique internationale, núm. 53, (2011), pp. 83-99.

Bruyère-Ostells, B., "Outil militaire et politique africaine de la France depuis 1960: tableau historiographique et perspectives de recherche", Relations internationales 2016/1, núm. 165, pp. 3-22.

Chafer, T. y G. Cumming, "Beyond Fashoda: Anglo-French security cooperation in Africa since Saint-Malo", International Affairs, 86, núm. 5 (2010), pp. 1129-1147.

Chafer, T., "Hollande and Africa Policy", Modern Ev Contemporary France, vol. 22, núm. 4 (2014), pp. 513-531.

Chaigneau, P., La politique militaire de la France en Afrique, París, CHEAM, 1984.

Charbonneau, B., "Dreams of Empire: France, Europe, and the New Interventionism, Africa”, Modern Eं Contemporary France, 16, núm. 3 (2008), pp. 279-295.

Charillon, F., "Vers la régionalisation de la politique étrangere", en Charillon, F. (dir), Politique étrangère : nouveaux regards, París, Presses de Sciences Po., 2002.

Chevénement, J.P. y G. Larcher, Rapport d'information fait au nom de la commission des affaires étrangères, de la défense et des forces armées, núm. 513 (2012-2013).

Claeys, A.S., La France et la politique africaine de l'Europe (tesis doctoral inédita), Universidad Bordeaux IV, 2004.

Cling J.P., "La Banque mondiale, entre transformations et résilience", Critique Internationale, 2011/4, núm. 53, pp. 43-65.

Cogan, C., "Puissance virtuelle : la France de la victoire à l'OTAN", 
en M. Vaïsse, Mélandri, P. y Bozo, F., La France et l'OTAN (19491966), Bruselas, Éditions Complexe, 1996.

Collombat, B., Au nom de la France: guerres secrètes au Rwanda, París, La Découverte, 2014.

Connelly, M., L'arme secrète du FLN, París, Payot et Rivages, 2014.

Davis, L., "Make do, or mend? EU security provision in complex conflicts: the Democratic Republic of Congo", European Security, 24, núm. 1 (2015), pp. 101-119.

De Lespinois, J., L'armée de terre française: de la défense du sanctuaire à la projection (vol. 2), París, L'Harmattan, 2001.

Defrance, C. y U. Pfeil, Le traité de l'Élysée et les relations franco-allemandes. 1945-1963-2003, París, CNRS éditions, 2005, pp. 73-87.

D'Epenoux, C. y C. Hoche, "Giscard l'Africain”, L'Express, 15-21 de diciembre de 1979, núm. 1484.

Desgrais N. y S. Le Gouriellec, Stratégies d'extraversion: Les défis de la construction de l'Architecture africaine de paix et de sécurité, Note de recherche stratégique, núm. 28 (2016), Irsem.

DiARRA, A., La gauche française et l'Afrique subsaharienne: Colonisation, décolonisation, coopération (XIXè-XXè siècles), París, Karthala, 2014.

Dijkstra, H., "The military operation of the EU in Chad and the Central African Republic: good policy, bad politics", International peacekeeping, 17, núm. 3 (2010), pp. 395-407.

Dimier, D., "Construire l'association de la communauté européenne et de l'Afrique indépendante", Matériaux pour l'histoire de notre temps, núm. 77 (2005).

Documentos de la diplomacia francesa,

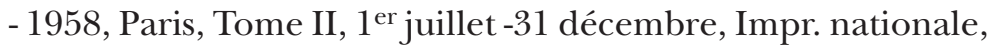
1993.

- 1959, Paris, Tome II, 1 er juillet -31 décembre, Impr. nationale, 1995.

- 1960, Paris, Tome I, 1 er janvier - 30 juin, Paris, Impr. nationale, 1995.

- 1966, Bruxelles, Tome I, 1 er janvier - 31 mai, PIE-Peter Lang, 2006.

Dumas R., La diplomatie sur le vif: dialogues avec Bertrand Badie et Gaïdz Minassian, París, Presses de Sciences Po, 2013. 
Dumoulin, A., La France militaire et l'Afrique, Bruselas, Ed Complexe, 1997.

DuRAND P.M., L'Afrique et les relations franco-américaines des années soixante: aux origines de l'obsession américaine, París, L'Harmattan, 2017.

Dyson, T., "The Material Roots of European Strategy: Beyond Culture and Values", Contemporary Security Policy, 34, núm. 3 (2013), pp. 419-445.

Favier, P. y M. Martin-Roland, La décennie Mitterrand, t.3: Les défis, París, Points, 2016a [1996].

Favier, P. y M. Martin-Roland, La décennie Mitterrand, t.1, Les ruptures, París, Points, 2016b [1990].

Featherstone, K. y C. Radaelli, The Politics of Europeanization, Oxford, University Press, 2003.

Foccart, J., Foccart parle, entretiens avec Philippe Gaillard, t. I, París, Fayard, Jeune Afrique, 1995.

Foccart, J., Foccart parle: entretiens avec Philippe Gaillard, t. II, París, Fayard, Jeune Afrique, 1997.

Foccart, J., Journal de l'Elysée, Dans les bottes du général, t. III, (19691971), París, Fayard, Jeune Afrique, 1999.

Gaulle C. de, Discours et messages. I, Pendant la guerre: juin 1940-janvier 1946, París, Plon, 1993.

Gaulme, F., "Intervenir au Mali: le retour du politique", Etudes, 418, núm. 5 (2013).

Gegout, C., "Causes and consequences of the EU's military intervention in the Democratic Republic of Congo: a realist explanation”, European Foreign Affairs Review, 10, núm. 3 (2005), pp. 427-443.

Gegout, C., "EU Conflict Management in Africa: The Limits of an International Actor", Ethnopolitics, 8, núms. 3-4 (2010), pp. 403-415.

Ginsberg, R.H., Foreign Policy Actions of the European Community The Politics of Scale, Boulder, Lynne Rienner Publishers, 1989.

Gounin, Y., La France en Afrique. Le combat des Anciens et des Modernes, Bruselas, De Boeck Supérieur, 2009.

Gregor, M., Les guerres africaines de François Hollande, París, Éditions de l'Aube, coll. L'urgence de comprendre, 2014. 
HäGE, F.M., "The scheduling power of the EU Council Presidency", Journal of European Public Policy, 24, núm. 5 (2016), pp. 695-713.

Haine, J.Y., "The Failure of a European Strategic Culture - EUFOR CHAD: The Last of its Kind?”, Contemporary Security Policy, 32, núm. 3 (2011), pp. 582-603.

Harbi, M., Les archives de la révolution algérienne, París, Jeune Afrique, 1981.

Haroche, P., "Interdependence, asymmetric crises, and European defence cooperation”, European Security, 26, núm. 2 (2017), pp. 226-252.

Heilbrunn. J. y W.M. Toulabor, "Une si petite démocratisation pour le Togo”, Politique africaine, núm. 58 (1995), pp. 85-100.

Holsti, K.J., "National Role Conception in the Study of Foreign Policy”, International Studies Quarterly, 14, núm. 3 (1970), pp. 233-309.

Howorth, J., "European Defence and the Changing Politics of the European Union: Hanging Together or Hanging Separately?”, Journal of Common Market Studies, vol. 39, núm. 4 (2001), pp. 765-789.

Hugo, S., "Le conflit ivoirien: enjeux régionaux et maintien de la paix en Afrique”, Politique étrangère, núm. 68-2 (2003), pp. 321-334.

Hynek, N., "EU crisis management after the Lisbon Treaty: civilmilitary coordination and the future of the EU OHQ", European security, 20, núm. 1 (2011), pp. 81-102.

Irondelle, B., La réforme des armées en France, París, Les Presses de Sciences Po, 2011.

Jouve, E., Le général de Gaulle et la construction de l'Europe (19401966), París, LGDJ, 1967.

Katzenstein, P., "International relations and domestic structures”, International Organization, vol 31, núm. 4 (2009), pp. 1-45.

Keukeleire S. y J. MacNaughtan, The Foreign policy of the European Union, Palgrave Macmillan, 2008.

KingaH, S. y L. van Langenhove, "Determinants of a regional organization's role in peace and security: the African Union and the European Union compared", South African Journal of International Affairs, 19, núm. 2 (2012), pp. 201-222. 
KInSEy Powell, N., "La France, les États-Unis et la Force interafricaine au Zaïre (1978-1979)", Relations internationales , 150, núm. 2 (2012), pp. 71-83.

Koepf, T., "Interventions françaises en Afrique: la fin de l'européanisation?”, Politique étrangère, núm. 2 (2012), pp. 415-426.

Krasner, S., Defending the National Interest: Raw materials investments and US foreign policy, Princeton, University Press, 1978.

LAsserre, I. y T. Oberle, Notre guerre secrète au Mali: les nouvelles menaces contre la France, París, Fayard, 2013.

Lucarelli, S. y I. Manners, Values and Principles in European Union Foreign Policy, Londres, Routledge, 2006.

MACLeOD, A., "L'approche constructiviste de la politique étrangere", en Frédéric Charillon (dir), Politique étrangère: nouveaux regards, París, Presses de Sciences Po., 2002.

MARCHAL, R., An assessment of EUFOR Tchad/Car in Walter Feichtinger y Gerald Hainzl, Viena, Institut fur Friedenssicherung und Konfliktmanagement, 2011, pp. 19-33.

Marchesin, P., "Mitterrand l'africain", Politique africaine, 58 (1995).

Masset, D. Une affaire internationale?, la Belgique et la guerre d'Algérie, 1954-1956, Louvain-la-Neuve, Ciaco, 1988.

Mattelaer, A., The Strategic Planning of EU Military Operations - The Case of EUFOR TCHAD / RCA. IES, 5/ (documento de trabajo), 2008.

MAYA, K., La Stratégie américaine en Afrique, Etude de l'IRSEM, núm. 36, diciembre de 2014.

MéDARD, J.F., "Le rapport de clientèle du phénomène social à l'analyse politique", Revue française de science politique, año 26, núm. 1 (1976), p. 108.

Meimon, J., En quête de légitimité: Le ministère de la coopération (19591999), (tesis doctoral inédita), Universidad Lille II, 2005.

Menon, A., "Empowering paradise? The ESDP at ten", International Affairs, 85, núm. 2 (2009), pp. 227-246.

Mény, Y. y Y. Surel, Politique comparée les démocraties : Allemagne, ÉtatsUnis, France, Grande-Bretagne, Italie, París, Montchrestien, 2009.

NASRA, S., Governance in EU foreign policy: exploring small state influence, Journal of European Public Policy, 18, núm. 2 (2011), pp. 164-180. 
Nivet, B., "Du laboratoire au miroir: quand l'Afrique subsaharienne construit l'Europe stratégique”, Politique africaine, vol. 127, núm. 3 (2012), pp. 135-153.

Notin., J-C., La Guerre de la France au Mali, París, Tallandier, 2014.

Nováky, N.I.M., "Deploying EU military crisis management operations: a collective action perspective", European Security, 24, núm. 4 (2014), pp. 491-508.

Olsen, G.R., "The ambiguity of US foreign policy towards Africa", Third World Quarterly, 38, núm. 9 (2017), pp. 2097-2112.

Oмiтоogun, W. y K. Onigu-Otite, Tise national conference as a model for democratic transition, Benin and Nigeria, Ibadan, IFRA, 1996.

Orsenna, E., Quinze ans après, Lettre de l'IFM, núm. 12, 2005.

Palayret, J.M., "Les mouvements proeuropéens et la question de l'Eurafrique, du Congrès de la Haye à la Convention de Yaoundé (1948-1963)", en M.T. Bitsch, G. Bossuat (dir), L'Europe unie et l'Afrique: de l'idée d'Eurafrique à la convention de Lomé I, Bruselas, Bruylant, 2005.

Panon, X., Dans les coulisses de la diplomatie française, de Sarkozy à Hollande, París, L'Archipel, 2015.

Paul, V., W. Larson y W. Wohlforth, Status in World Politics, Cambridge, University Press, 2014.

Penne, G., Mémoires d'Afrique, (1981-1998), París, Fayard, 1999.

Perrot, S., "Les nouveaux interventionnismes militaires africains. Une redéfinition des conditions de la puissance au sud du Sahara”, Politique africaine, 98, núm. 2 (2005), pp. 111-130.

Posen, B., "European Union security and defence policy: response to unipolarity?", Security studies, 15, núm. 2 (2006), pp.149-186.

Raimero, R. "L'Italie entre amitié française et solidarité algérienne”, en J.P. Rioux (dir), La guerre d'Algérie et les français, coloquio del Institut d'histoire du temps présent (París, 15-17 de diciembre de 1988), París, Fayard, 1990.

Rayroux, A., “Adaptation, projection, convergence: L'européanisation de la défense et l'intervention militaire EUFOR Tchad/ RCA”, Politique européenne, 34, núm. 2 (2011), pp. 201-230.

Revault D'Allones, D., Les Guerres du président, París, Éditions du Seuil, 2015. 
Riddervold, M., "Finally, flexing its muscles? Atalanta-The European Union's naval military operation against piracy", European Security, 20, núm. 3 (2011), pp. 385-404.

Riddervold, M., "New threats - different response: EU and NATO and Somali piracy”, European Security, 23, núm. 4 (2014), 546-564. Risse, T., "Public opinion, domestic structure and foreign policy in liberal democracies", World politics, vol 43, núm. 4 (1991), pp. 479-512.

Rouppert, B. Tisseron, A., "De la méditerranée au Sahel: la sécurité d'abord", en Abdennour Benantar, La sécurité en Méditerranée occidentale: face aux bouleversements au Maghreb et au Sahara, París, L'Harmattan, 2015, pp. 11-29.

Roussel, E., Georges Pompidou, París, JC. Lattès, 1984.

SADA, H., "Le conflit ivoirien: enjeux régionaux et maintien de la paix en Afrique”, Politique étrangère, núm. 2, 2003, p.321-334.

Schimmelfennig, F. y D.C. Thomas, "Normative Institutionalism and EU Foreign Policy in Comparative Perspective", International Politics, 46, núm. 4 (2009), pp. 491-504.

Schmit, O., "Strategic Users of Culture: German Decisions for Military Action”, Contemporary Security Policy, 33, núm. 1 (2012), pp. 59-81.

SEAU, "Sahel: l'UE mobilise 414 millions d'euros pour l'aide internationale" (comunicado conjunto), 23 de febrero de 2018, https://europa.eu/rapid/press-release_IP-18-1142_fr.htm

Shaun, G., "The French Military in Africa: Past and Present", African Affairs, vol. 99, núm. 396 (2000), pp. 435-448.

SJursen, H., "Why Expand?: The Question of Legitimacy and Justification in the EU's Enlargement Policy", JCMS: Journal of Common Market Studies, 40 (2002), pp. 491-513.

Sмiтн, S., "La politique d'engagement de la France à l'épreuve de la Côte d'Ivoire", Politique africaine, vol. 89 núm. 1 (2003), pp. 112126.

Smith, M.E., Europe's Foreign and Security Policy: The Institutionalisation of Cooperation, Cambridge, University Press, 2004.

Snyder, G., "The Security Dilemma in Alliance Politics", World Politics, 36, núm. 4 (1984), pp. 461-495.

Soutou, G.H., La guerre froide, París, Fayard, 2013. 
St. John, R. B., Libya and the United-States, Philadelphia, University of Pennsylvania Press, 2002.

Stora, B., Le mystère de Gaulle: son choix pour l'Algérie, París, Robert Laffont, 2009.

Treacher, A., "From Civilian Power to Military Actor: The EU's Resistable Transformation”, European Foreign Affairs Review, vol. 9, núm. 1 (2004), pp. 49-66.

Tull, D., La cooperation franco-allemande au Sahel: conséquences et perspectives du 'tournant africain' de l'Allemagne, Notes de recherche núm. 45, Irsem, 2017.

Turpin, F., De Gaulle Pompidou et l'Afrique, 1958-1974, Décoloniser et coopérer, París, les Indes savantes, 2010.

VAÏsse, M., P. Melandri y F. Bozo, La France et l'OTAN (1949-1966), Bruselas, A. Versailles, 2012.

VAïsse, M., La Grandeur: politique étrangère du général de Gaulle, París, CNRS Éditions, 2013 [1998].

VÉdrine, H., Les mondes de François Mitterrand: à l'Elysée 1981-1995, París, Fayard, 1996.

VeenendaAl, W. P., "Analyzing the foreign policy of microstates: the relevance of the international Patron-Client model", Foreign Policy Analysis, 13 (2017), pp. 561-577.

Weiss, M., "Transaction costs and the establishment of the European security and defense policy", Security studies, 21, núm. 4 (2012), pp. 654-682.

Westad, O. A., The Global Cold War: Third World Interventions and the Making of Our Times, Cambridge, University Press, 2005.

Wilde D'Estmael, T., "L’Union européenne et la résolution des conflits dans Remacle”, en Eric V.B. Rosoux, L. Saur, L'Afrique des Grands Lac: des conflits à la paix ? (coloquio organizado en noviembre de 2003 en Bruselas por la Chaire Bernheim Paix y la ciudadania de la ULB, le Centre d'étude des crises et des conflits internationaux de la UCL, CECRI y el Centre de recherche en science politique des FUSL), Bruselas, PIE-P, Lang, 2007.

Yakemtchouk, R., La Belgique et la France, Amitiés et rivalités, París, L'Harmattan, 2010. 
